\title{
INFLUÊNCIA DE PORTA-ENXERTOS E COPA NA PRODUTIVIDADE DA MANGUEIRA (Mangifera indica L.)
}

\section{ORLANDINA NYLANDER BRITO OHASHI}

Engenheisa Agrônoma

Orientador: Dr. SALIM SIMĀO

Dissertação apresentada à Escola Superior de Agricultura "Luiz de Queiroz", da Universidade de São

Paulo, para obtenção do título de Mestre em Agronomia, Área de Concentração: Fitotecnia.

\footnotetext{
PIRACICABA

Estado de São Paulo - Brasil Junho - 1984
} 
.ii.

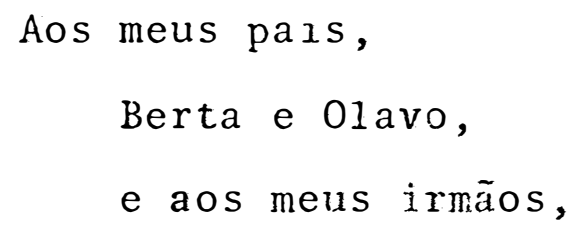

OFEREÇO.

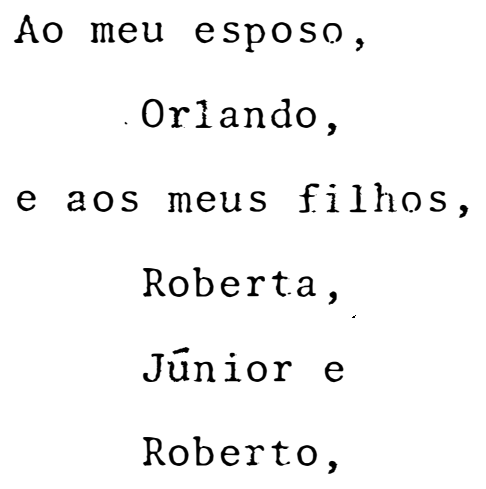

DEDICO . 
.iii.

\section{AGRADECIMENTOS}

A autora expressa seus agradecimentos a todas as pessoas e instituições que direta ou indiretamente colabora ram para a realização deste trabalho, especialmente:

- Ao Prof. Dr. Salim Simão, pela orientação, amizade e constan te incentivo durante o curso e na execução deste trabalho;

- A Escola Superior de Agricuitura "Luiz de Queiroz", da Univer sidade de Säo Paulo, Piracicaba, SP, pela oporturidade de aperfeiçoamento;

- Aos Professores do Departamento de Agricultura e Horticultura, pelos ensinamentos transmitidos;

- Aos Engenheiros Agrōnomos Orlando Shigueo Ohashi e Ronaldo Veloso Naves, pela ajuda na condução do trabalho;

- Aos colegas do curso de Pós-Graduação, pelo incentivo, amiza de e sugestões durante o curso;

- Ao Prof. Dr. Antonio Joaquim de Oliveira, pela versão do resumo para o inglès; 
- Aos Professores Dr. Décio Barbin, Dr. Irineu H. Packer e Engenheira Agrônoma Eliana A. Schammass, pelas anālises estatisticas;

- Aos funcionārios do Setor de Horticultura, em especial aos Srs. Antonio Gibelli e Reinaldo Belline pela colaboração na execução do experimento;

- Aos funcionários da Biblioteca da ESALQ/USP, em especial ao Sr. Luiz Carlos Veríssimo, pela solicitude no atendimento.

- À CAPES, pela concessão da bolsa de estudo. 


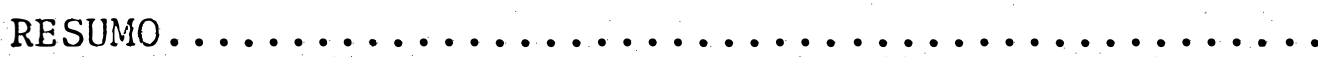

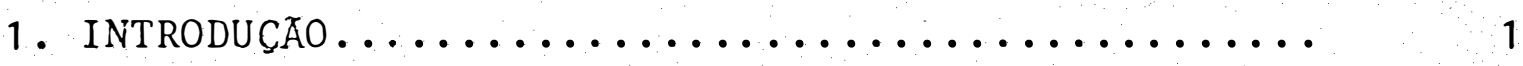

2. REVISAO DE LITERATURA................. 4

2.1. Vegetação..................... 4

2.2. F1orescimento................. 6

2.3. Frutificação................... 9

- 2.4. Indice de frutificação............... 12

3. MATERIAL E METODOS.................... 15

3.1. Localização e clima................ 15

3.2. Variedades.................... 16

3.3. Delineamento experimental........... 19

3.4. Avaliação do experimento........... 19

3.5. Análise estatística............... 20

4. RESUltAdOS E DISCUSSAO ............... 22

4.1. Vegetação, florescimento e frutificação.... 22

4.2. Altura e diāmetro das copas............. 28

4.3. Nümero de frutos................. 31

5. CONCLUSOES....................... 37

6. Literatura citada...................... 39

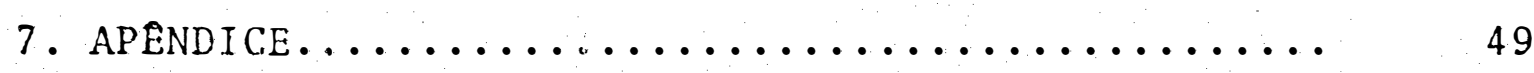


.vi.

\title{
INFLUENCIA DE PORTA-ENXERTOS E COPA \\ NA PRODUTIVIDADE DA MANGUEIRA (Mangifera indica L.)
}

\author{
ORLANDINA NYLANDER BRITO OHASHI \\ - AUTOR -
}

ORIENTADOR: DR. SALIM SIMÃO

\section{RESUMO}

Este trabalho foi realizado no pomar da Escola Superior de Agricultura "Luiz de Queiroz", da Universidade de São Paulo, com o objetivo de verificar a influência da combina çao copa $x$ porta-enxerto na produtividade da mangueira. A altu ra e diâmetro da copa, foram medidos em 1981, e ainda foram ob servados o número de panículas e o número de frutos durante os anos de 1981 a 1983 em 210 plantas que no inicio do experimento estavam com 15 anos de idade. As plantas tëm como porta-enxertos as variedades Extrema, Espada, Oliveira Neto, Carlota, Bour bon, Coco e Pahiri e como copa as variedades Extrema, Pahiri, Imperial, Oliveira Neto, Carlota e Bourbon. Os dados foram ana lisados estatisticamente segundo o programa LSMLGP ("Least - 
pas mais produtivas são 'Carlota' e 'Oliveira Neto', que tambêm revelaram-se como os melhores porta-enxertos para a copa de 'Carlota', com indice de frutificação de 6,3 e 6,4 frutos $/ \mathrm{m}^{2}$ de copa, respectivamente. A produção de frutos nos anos de 1981 e 1983 foi influenciado pela variedade de copa, enquanto que no ano de 1982, foi influenciado pela variedade do porta-enxerto. A interação copa $x$ porta-enxerto não influenciou na produção. 
.viii.

\title{
INFLUENCE OF ROOTSTOCK AND SCION ON MANGO \\ (Mangibera indica L.) PRODUCTIVITY
}

\author{
ORLANDINA NYLANDER BRITO OHASHI \\ - AUTHOR -
}

\section{ADVISER: DR, SALIM SIMÃO}

\section{SUMMARY}

This work was conducted in the Escola Superior de Agricultura "Luiz de Queiroz" orchard and was undertaker to investigate the influence of the combination of scion $x$ rootstock in the mango tree productivity. The trees hight and scion diameter were measured once in 1981 and the number of panicles and the number of fruits were determinate from 1981 to 1983, using 210 trees with 15 years old at the begining of the experiment. The Extrema, Espada, Oliveira Neto, Carlota, Bourbon, Coco and Pahiri varieties were used as rootstock and the varieties Extrema, Pahiri, Imperial, 01iveira Neto, Carlota and Bourbon were utilized as scion. The results were statjstically analised by the LSMLGP Harvey program (Least, Maximum Likelihood General Purpose). The scion of Carlota and Oliveira Neto varieties showed the highest productivity, and were also the best rootstock 
for the Carlota scion, that showed a frutification rat of 6.3 to 6.4 fruits $/ \mathrm{m}^{2}$ respectively. The fruit productions in the 1981 and 1983 varied according to scion variety, while in 1982 the fruit productions varied according to rootstock. The interaction scion $x$ rootstock did not have any influence on fruit production, as statistically demonstrated. 


\section{IIUTRODUCÁ̃O}

A mangueira (Mangifera indica L.) è considerada como originária da região Indo-Burma (SINGH, 1968), onde pređo mina principalmente o clima monçonico, que se caracteriza por duas estações bem distintas, uma bem chuvosa e outra bem seca (CAMARGO e.t alii, 1977).

Presume-se gue esta planta è cultivada hả mais de 6.000 anos na India, de onde em tempos remotos se estendeu ao Vietnan, paquistão, Srilanka e Indonésia; nos séculos XVI e XVII foi introduzida nas Filipinas, América Central e sul e Leste da Äfrica. Hoje, seu cultivo se estende por toda a faixa tropical do mundo e tambëm algumas regiöes subtropicais, numa faixa de latitude que vai desde $31047^{\prime} \mathrm{N}$ até $33056^{\prime} \mathrm{S}$ (SIMÃo, 1980a).

Nas Américas, o primeiro paîs a cultivâ-la foi o Brasil (DE CANDOLLE, 1959). As primeiras plantas dessa espé- 
cie vieram da África no século XVI, trazidas pelos portugueses e plantadas na cidade do Rio de Janeiro, donde se difundiram para todo o país (MORALES, 1971; SIMRO, 1971).

Considera-se a manga como uma das três frutas tropicais mais importantes do mundo; além de ser uma planta econômica, quando completamente desenvolvida, é uma das ärvores mais exuberantes.

A India é o maior produtor de manga, com $63 \%$ do total mundial, seguindo-se o México, Brasil, Paquistão e Filipinas, com 4,$6 ; 4,5 ; 4,0$ e $2,8 \%$ da produção mundial, respectivamente (FAO, 1981).

O Brasil, com exceção dos Estados do Sul e de faixas litorâneas do Estado de São Paulo, possui condições eco lógicas bastante favoráveis para a produção econômica da manga (SIMAO, $1980 \mathrm{~b})$. Os estados maiores produtores, segundo o IBGE (1982) são: Minas Gerais, Pernambuco, Cearä e Bahia; estando esta frutífera em 5 o lugar em área cultivada, sendo superada a penas pela laranja, banana, caju e uva.

A manga possui diversidade de usos, sendo o seu princjpal consumo, o de frutas frescas, podendo ser utilizada na indústria de alimentos no preparo de doces, conservas, pastas e geléias. O amido do caroço é um subproduto em potencial dos resíduos da industrialização da manga; possui ainda propriedades medicinais como laxativa, diurética e revigorante. Sua composição química varia com as condições da cultura, variedade e estảgio de maturação, entre outros fatores. Porém, de 
uma maneira geral, a fruta fresca, possui alto teor de sóli dos solúveis totais e alto teor de açúcar (ITAL, 1981). Apesar da manga ser considerada uma das mais im portantes frutas tropicais do mundo, a literatura a respeito de suaprodutividade é reduzida, limitando-se a aspectos mais especí.. ficos, sem abranger fatores integrados como, influência de por ta-enxerto na produtividade. Dado a importância dessa frutífera, propôs-se neste trabalho, atravēs de estudos de campo, verificar a influência de porta-enxerto e copa na produtividade da mangueira. 


\section{REVISÃO DE LITERATURA}

Neste trabalho é abordada apenas literatura sobre vegetação, florescimento e frutificação, por não terem sido encontrados trabalhos relacionados diretamente com o assunto de porta-enxertos.

\subsection{VEGETAC.̃̃O}

A literatura sobre biologia de mangueira mostra que a ocorrência de surtos vegetativos apresenta periodicidade marcante, com período de vegetação ativa, seguido por outro sem vegetação, e segundo SIMÃo (1960), variam em nümero e aparecen em diferentes epocas influenciados pelo clima, variedades e tratos culturais, mas de uma maneira geral se inicia anualmente em agosto e termina seu ciclc em fevereiro. 
RUEHLE e LEDIN (1955), dizem que os surtos vege tativos na Flórida, ocorrem principalmente na primavera e verão, quando se desenvolvem i a 3 ou mais surtos.

BUELL e HONS (1954), observaram que nas regiões secas, ocorrem normalmente 1 ou no mäximo 2 surtos vegetativos ativos durante o ano e em regiões ümidas as diferentes varieda des podem apresentar de 2 a 6 surtos vegetativos por ano.

Krishnamurthi et alii, citados por PRASAD e PATAK (1970), na India, verificaram 5 surtos de gemas vegetativas nas variedades Dashehari e Chausa, sendo que o principal 으 correu de março a maio.

SEN e MAITJ. (1969) observaram que as quatro estações apresentavam condições favoráveis para o aparecimento de surtos vegetativos em Bengal, sendo que as variedades Langra, Bombain e Fazli produziram no máximo 3 surtos e a maioria dos ramos se desenvolveu na prinavera.

SIMAO (1960) e PRASAD e PATAK (1970) citam que em 1935 Galang e Lazo verificaram que os ramos têm que atingir um certo comprimento, diâmetro, número e tamanho de folhas para produzir panículas; em 1938, os mesmos autores tinham dúvidas de que os ramos frutiferos estivessem associados à vegetação; entretanto, em 1959, Singh não observou relação entre com primento, diâmetro e nümero de folhas por ramo e formação de panículas, afirmando que seu estímulo è independente de tama nho e maturidade dos ramos.

Alguns autores acreditam que haja necessiclade 
de um intervalo entre os surtos vegetativo e florescimento, pa ra que os ramos atinjam uma certa maturidade; SIMAO (1956) verificou que cada período vegetativo tem duração de 30 a 45 dias, sendo que os primeiros 15 a 20 dias são gastos no desenvolvimento dos ramos em comprimento e diâmetro e os restantes para completar a maturação do ramo encerrando seu período vegetativo.

SWAWKY et alii (1980), na cidade do Cairo (Egito) trabalhando com mangas da variedade Taimour, notaram que dos três brotamentos de primavera, verão e início de outono, os mais abundantes e que produziram a maioria das inflorescências foram os brotamentos de verão.

\subsection{FLORESCIMENTO}

SIMAO (1960) diz que o florescimento se dá por períodos sendo os mais importantes os ocorridos de junho a agosto, podendo ser antecipado ou retardado em função do clima e da produtividade das plantas do ano anterior.

Em Viçosa, MG, RODRIGUES et alii (1977) determi naram o período de florescimento de 10 cultivares de manga, com seu início em meados de junho, prolongando-se até meados de ou tubro, durante 120 dias, sendo que cada cultivar floresce em mëdia 57 dias.

RUEHLE e LEDIN (1955), na FIörida, observaram 
que as inflorescências são produzidàs de dezembro a março (inverno), dependendo das condiçōes climáticas e da variedade.

SEN (1944), observou que a atividade vegetatj.va da mangueira se inica anualmente com o aparecimento das inflorescências no inverno, marcando assim o começo de uma nova eta pa, na primavera aparece uma brotação vigorosa, seguida por ou tra no verão, podendo ocorrer uma terceira no fin das chuvas.

Naik e Rao, citados por DONI (1974) observaram que o início do florescimento da mangueira é de caräter varie tal, sendo influenciado pela temperatura, a qual pode adiantar ou atrasar o florescimento.

Enquanto MANICA (1981) afirma que o florescimen to pode ser antecipado ou retardado em função da produtjvidade da safra anterior e da percentagem de ägua disponível no solo; plantas pouco produtivas num ano podem ter seu florescimento antecipado no ano seguinte, enquanto plantas muito produtivas num ano podem atrasar seu florescimento no ao seguinte; em reIação à ảgua disponível no solo, verificou que a mangueira prọ duz poucos botōes florais em invernos ümidos, pois a ägua disponível no solo estimula principalmente o crescimento vegetat vo.

SILVA (1982) afirma que a diferenciação floral se processa logo após o final da estação chuvosa e o florescimento ocorre durante os meses secos.

SHAWKY e ZIDAN (1978) dizem que na variedade Zebda, no ano que não frutifica, a árvore não floresce total- 
mente.

Para BUELL e HONS (1954) em região úmida, fatores nutricionais podem inibir a floração como: conteúdo de car boidratos durante ò período de início de floração e excesso de nitrogênio em presença de umidade adequada do solo. Jả SINGH (1968) acha que fatores nutricionais dos ramos não podem ser correlacionados com a formação de botões florais.

SIMĀO (1971) e SILVA (1982) consideram que a luu minosidade é de extrema importância para a produção da mangue $\underline{i}$ ra, já que esta necessita de muito sol para florescer e frutificar; quando cultivadas em espaçamento inadequado florescem porèm, não frutificam.

A polinização das flores da mangueira ée muito deficiente, não ultrapassando a $12 \%$ na natureza (LYNCH e MUSTARD, 1955).

A baixa fertilização é atribuída a pequena eficiência dos agentes polinizadores (SIMAO e MARANHAO, 1959 e SINGH, 1964). Conforme SINGH (1960) a polinização é feita, qua se exclusivamente por moscas.

A distribuição de flores nas panículas, se dá, segundo POPENOE (1917), numa proporção que varia com a variedade; jā para SPENCER e KENNARD (1956) varia com as condições am bientais e época de emergência das panículas; enquanto que para SINGH (1964) esta variação se dá com a idade da planta; MAL LIK (1957) e WOLFE et alii (1969) afirmam que esta variação se dá de ano para ano. 


\subsection{FRUTIFI ICACÃO}

As mangueiras sao plantas muito conhecidas pelas suas constantes falhas na frutificação e pela sua frutificação irregular, apresentando muitas vezes pequena frutifica ção mesmo quando as plantas tenham florescido, abundantemente (MANICA, 1981).

AVILĀN (1971), explica a alternância na produção pela variação das concentrações dos elementos nutritivos, logo após um ano de alta produção, onde a exigência foi máxima, os níveis alcançados durante a fase de acumulação não são elevados, o qual repercute na baixa floração do ciclo seguinte; o que è concordado por MORALES (1971) que diz que a alternância de altos rendimentos é explicado em parte, por concorrência em nutrientes e consequente redução do crescimento vege tativo nos anos de alta produção.

Segundo Yee, citado por DONI (1974), o hábito de frutificação da mangueira ê dependente de fatores como a va rièdade, práticas culturais e condições ambientais; enquanto JAWANDA e SINGH (1961) afirmam que a capacidade para produzir depende da idade, do estado nutricional e sanidade da planta, tendo papel secundärio os caracteres varietais.

AVILAN et alii (1981) dizem que existe uma marcada tendência a incrementar-se a produção nos primeiros anos, alcançando sua máxima entre o 109 e o 14 ! anos de idade, com o passar dos anos, há uma tendência a diminuir e aos $18 \%$ a $20 \underline{\text { a }}$ 
nos de idade estaria no início de um período de produçäo decrescente.

As causas da irregularidade de frutificação dependem de inümeros fatores, entre eles fisiológicos, climáti cos e culturais (SINGH, 1948; ROY, 1953; SIMAOO, 1956).

Para SEN (1944), a produção irregular tem como causa a reduzida vegetação da mangueira, após um intenso perío do de florescimento e frutificação; jā para COBIN (1950), BUCKK LEW (1957) e SIMÃO (1957), os agentes responsáveis por esta ir regularidade são: a temperatura e doenças no período do flores cimento. KENNARD e SPENCER (1956), mencionam ataque de insetos, principalmente trips enquanto RODRIGUES (1922) e SINGH (1964) acham que é devido a baixa proporcão de flores férteis. Segundo SINGH (1964), a polinização deficiente e chuvas abundantes durante o florescimento favorecem a presença de fungos que determinam a queda das flores, por outro lado para NAKASONE et ali. (1955) na var. Pahiri o ciclo bienal parece ser resultado de um longo intervalo entre os surtos vegetativos e o florescí mento, ou seja, problemas tipicamente fisiológicos.

Chuvas prolongadas durante o período de florescimento danificam tanto as flores abertas, quanto as fechadas, arrastando grande parte da quantidade de pólen, em virtude dis so, hã uma grande floração e pequena frutificaçāo (GARDNER et alii, 1927; WERNER, 1936).

BARNELL (1939); WOLFENBARGER (1957) e SIMAOO (1958) verificaram que de centenas de frutos existentes ini- 
cialmente na panícula, normalmente um só e excepcionalmente dois frutos chegam ao final do ciclo.

BUELL (1954) diz que a produção de frutos é inversamente proporcional ao número de brotações por ano.

SIMÃO (1960) em experimentos feitos nos anos de 1950 e 1959, em Piracicaba, verificou que as variedades mais produtivas foram: Oliveira Neto, J.F. Silva, Brasil, Itamaracá e Espadão, tendo observado também que dos elementos climáticos, a chuva é a mais desfavorāvel à frutificação, pois, a produção foi diminuída nos anos chuvosos; sendo que a mangueira se caracteriza por produzir poucos frutos em relação a quantidade de flores.

A mangueira necessita de uma alteracão de estações seća e úmida, para que ela possa produzir economicanente (BRUNINI e ALFONSI, 1980). O período de seca deve ocorrer um pouco antes da época do florescimento, devendo continuar até o início do desenvolvimento dos frutos (WOLFE et alii, 1969).

Em locais onde chove demasiadamente, a mangueira a presenta um desenvolvimento vegetativo muito grande às expensas da frutificação (SINAXO, 1960; SINGH, 1975). Em regiões mui to úmidas, essa cultura não produz tão bem como em regiões mais secas, pois a umidade relativa do ar elevada, prejudica a poli nização e favorece a disseminação de doenças (PRATES e CANPOS, 1978).

SIMÃO (1960), afirma serem os períodos de florescimento e frutificação em que a ação do clima se faz sentir 
com maior intensidade e que umidade, chuvas, cerração e baixa temperatura durante o florescimento, se constituen nos mais impor tantes e frequentes agentes responsāveis pela baixa frutifica ção .

Segundo WOLFE et alii (1969), em geral, se pode mencionar que o número de frutos por planta varia muito, depen dendo entre outros fatores, do tamanho do fruto. Para ärvores com um mesmo tamanho de copa, as variedades com frutos de tama nho grande terão menos frutos que as variedades com frutos me dianos ou pequenos.

\section{4. İNDICE DE FRUTIFICAÇÃO}

De acordo com os hábitos gerais de crescimento, floração e localização dos frutos nas espécies frutícolas pere nes, é possível associar a forma de copa das árvores a figuras geométricas, permitindo este fato, calcular ou estimar a super fície de produção que existe em cada planta, conseqüentemente, a produção por unidade de superfície.

Em relação a manga, AUBERT (1975), diz que a c으 pa é um "cilindro" que tem como superfície de revolução «Dh, donde "D" é igual a mëdia dos diâmetros N.S. e E.D. e "h" a a 1 tura da planta, Avilān e Mazzi, citados por AVILĀN (1980), con sideram como copa ütil da ārvore, a contida em um "cone trunca do", ao determinar que a produção que está contida no ảpice da 
planta é desprezível e que cerca de $98 \%$ da produção está na parte média da copa da ārvore.

A superficie lateral da figura geométrica que assume uma determinada espécie, permite estabelecer una relação entre esta superfície e o número de frutos contidos na mes ma. Esta relação define a eficiência produtiva em qualquer momento da vida da planta, em geral, ou dentro de um ciclo ou ano de produção, em particular. Esta relação se denomina "índice de frutificação" (AVILĀN, 1980).

A copa da mangueira possui, segundo AUBERT e LOSSOIS (1972), a forma de bola ou fuso, a figura geométrica que mais se assemelha é o cone truncado, cuja fórmula da super fície è $S L=\pi(R+r) \sqrt{(R-r)^{2}+h^{2}}$, onde $\pi=3,1416 ; \mathrm{h}=$ altu ra; $R=$ raio inferior; $r=$ raio superior. Para simplificar em parte os cảlculos da superfície da figura geométrica adotada, a altura do cone "h" é $66 \%$ da altura total da árvore e o raio su perior " $r$ " da mesma é $56 \%$ do raio inferior " $R$ " (Avilän eMazzi, citados por AVILĀN, 1980).

Três períodos definidos foram determinados (AVI LAN et alii, 1981): (a) período compreendido entre os 2 e 8 anos de idade: o indice de frutificação vai se incrementando acentuadamente passando de 1,8 frutos $/ \mathrm{m}^{2}$ a 7,6 frutos $/ \mathrm{m}^{2}$. Quando a planta apresenta um acentuado incremento da superfície de producão ou copa, caracterizando-se este período por uma eleva da eficiência produtiva; (b) período compreendido entre os 8 e 15 anos de idade: durante este período, a planta mostra sua má 
xima capacidade reprodutiva e consequentemente sua maior eficiência, o indice de frutificação alcança valores de 10,3 frutos $/ \mathrm{m}^{2}$; (c) período que se inicia a partir dos 18 a 20 anos de idade da planta: período dos rendimentos decrescentes, donde a planta se caracteriza por um incremento de sua ineficiência re produtiva. O indice de frutificação passa de 5,5 frutos/m a valores de 2,6 e 2,1 frutos $/ \mathrm{m}^{2}$ a idades de 26 a 28 anos, respectivamente.

A vida comercial da planta, de acordo com os re sultados alcançados por AVILĀN (1980), está ao redor dos 25 anos de idade, enquanto GAILLARD (1978), estabelece-no entre 25 e 50 anos.

Avilān e Figueroa, citados por AVILA̛N (1980), clas sificaram algumas variedades de manga, de acordo com o indice de frutificação, empregando como valores referentes aos obtidos na variedade Haden, geralmente considerado uma das mais pro dutivas do seu país (Venezuela). 
.15.

\section{MATERIAL E MÉTODOS}

\subsection{LOCALIZACẼO E CLIMA}

0 ensaio foi conduzido no pomar do setor de Hor ticultura do Departamento de Agricultura e Horticultura da Escola Superior de Agricultura "Luiz de Queiroz" - ESALQ/USP.

O solo, segundo RANZANI et alii (1966), pertence ao grande grupo Latossolo, sêrie "Luiz de Queiroz", con topografia levemente ondulada.

O clima de Piracicaba, SP é Cwa pela classificação de Köppen (SETZER, 1967), ou seja, mesotérmico ümido, subtropical com inverno seco. As informações agrometeorológicos do local, foram fornecidas pelo Departamento de Física e Meteorologia da ESALQ, quais sejam: longitude 47038'00'"W, latitude $22^{\circ} 42^{\prime} 09^{\prime \prime S}$, altitude de $540 \mathrm{~m}$; as médias de temperatura, precí pitação e umidade relativa durante o transcorrer do experimen- 
to encontram-se nas Tabelas 14,15 e 16 do Apêndice.

\subsection{VARIEDADES}

Foram utilizados como copa, seis cultivares: Ex trema, Pahiri, Imperial, Oliveira Neto, Carlota e Bourbor enxertadas sobre: Espada, Extrema, Oliveira Neto, Caxlota, Bour bon, Coco e Pahiri.

Algumas características físicas das variadades utilizadas nesta pesquisa:

- EXTREMA: ärvore ereta, vigorosa e produtiva. Folha de limbo plano simêtrico, base acuneada e ápice em forma de sovela, cor verde-amarela em ambas as faces, as novas são avermelhadas. o fruto é grande, ovado-reniforme, pesando em média 350 a $400 \mathrm{~g}$, cavidade rasa onde se insere o pedünculo, äpice acentuado, superfície lisa, casca fina de cor amarela com äreas esverdeadas, polpa amarela, aquosa, quase sem fibras, modera damente terebentinosa e de sabor agradável. A semente é gran-de de forma ovalada-oblíqua e fibrosa. De boa qualidade para consumo ao natural e para o processamento (SAMPAIO, 1980).

- PAHIRI: cultivar nativa do Estado Maharashtra. Arvore alta, vigorosa, aberta, produtiva, com produção regular e alternan te. O fruto é de tamanho médio $(240$ a $300 \mathrm{~g})$ e de forma 
ovada. A base é obliquamente achatada, com um pedúnculo inserido no centro. O bico é do tipo longo e mamilado; o ápice ar redondado. A casca do fruto é média a grossa coriácea, cor de damasco, com lenticelas pequenas e de cor clara. A polpa é mo le, isenta de fibras, muito doce, de bom sabor, com suco abun dante. Produz muito cedo, com frutos de boa qualidade, mas de média a fraca conservação (KNIGHT Jr., 1980).

- IMPERIAL: Arvore de porte mëdio, crescimento lento. Folha com limbo plano, com leves ondulações, base acuneada, ápice mucro nulado, folha grossa, pouco lustrosa de cor verde, brotos novos bronzeados. O fruto possui tamanho grande $(320$ a $394 \mathrm{~g})$ de forma arredondada, base arredondada, pedúnculo assentado mais para o $1 \underline{a}$ do dorsal, ápice largamente arredondado, "neck" pouco evidente, casca grossa de cor verde-anarelada, polpa macia sem fibras, de sabor agradável e cor amarela, com semente de tamanho médio, apresentando poucas fibras e 5 veios bem salientes, transversais ao eixo (SIMAO, 1955).

- OLIVEIRA NETO: Árvore de porte elevado e rápido desenvolvimen to. Folha com limbo plano, base arredondada, ápice mucronulado, espessura grossa, brilhante de cor verde-escura, sendo as folhas novas bronze claro. Fruto de tamanho mëdio de forma ovada arredondada, pesando de 200 a 300 g, base arredondada com 
cavidade onde se insere o pedúnculo, apresenta sulco no terço superior até a cavidade basal, äpice arrendondado, "neck" proe minente, superfície lisa; casca fina de cor amarela esverdeada; polpa macia, sem fibra, levemente acidulada, de ötimo sabor, cor amarelo vivo; fruto tardio; semente de tamanho médio, pouco fibrosa, com 7 veios deprimidos em posição parela ao eixo (SIMAO, 1955).

- BOURBON: Ārvore de porte médio e vegetação densa. Folha de base arredondada, āpice agudo, lustrosa, as novas avermelha das. O fruto é de tamanho médio, forma ovada-cordiforne com . peso médio em torno de $300 \mathrm{~g}$, base arredondada, face dorsal onde se insere o pedúnculo menos levantada, superfície lisa, casca grossa, de cor verde anarelada que se destaca com faci lidade, polpa sucosa, amarela com fibras compridas, sabor agradável, sub-ácida e terebentinosa, de boa qualidade para consumo ao natural. Semente de tamanho médio oblonga e bastante fibrosa (SAMPAIO, 1980).

- CARLOTA: Ārvore de grande porte, vigorosa, folhagem densa e muito produtiva. Folha pequena, oval lanceolada, ondulada, $1 \underline{\text { i }}$ geiramente dobrada, do tipo obtuso para o agudo. Cor vermeTha das novas brotações. O fruto é de tamanho médio (150 a 200g), oval-ar redondado com a base e o ápice arredondados, pedünculo inserido perpendicularmente, cavidade rasa, bico redondo, casca verde amarelada de face ventral ligeiramente levantada, a 
dorsal termina em uma longa curva, polpa de cor amarela, conn sistente, sub-äcida, terebentinosa, com pequenas fibras e mo deradamente sucosa. Semente grande, oval-arredondada, com fi bras curtas na face ventral. Qualidade regular, boa para con sumo ao natural e para o processamento. De meia estação e tardia (SAMPAIO, 1980; RAMOS, 1982).

\subsection{DELINEAMENTO EXPERIMENTAL}

\subsection{Avaliaç̃o DO experimento}

0 experimento foi avaliado em um pomar instalado em 1966.

Durante a condução do experimento, os dados foram coletados para avaliaça da melhor combinação copa x por ta-enxerto, influenciando na produção. O efeito dos djferentes 
tratamentos foi avaliado atravês da contagem do número de paní culas e do número de frutos, nos anos de 1981,82 e 83 e medidas de altura e diâmetro da copa em 1981. Esses parâmetros foran medidos de acordo com a metodologia de Avilän e Mazzi, citados por AVI LĀN et alii (1981).

O período de maio a setembro, segundo SINFO (1960) e RODRIGUES et alii (1977), são os meses de maior florescimento, dai as contagens terem sido feitas nesta época. Foj estabe lecido o dia 21 de cada mês, para não haver interferência nos surtos floríferos, pois conforme SIMÃ (1960), as flores perma necem abertas apenas durante 3 semanas.

Os frutos foram contados em outubro de cada ano e as panículas nos meses de maio a setembro.

A percentagem de vegetação foi feita por observação visual atribuindo-se nota zero para ausência de vegetação nova e de 25 a 100 de acordo com a intensidade de vegetação.

A percentagem de frutos, foi calculada por:

$\frac{N F \times 100}{N P}$, onde $N F \bar{e}$ o número de frutos e NP o número de pa nículas.

A relação panĩcula/fruto foi calculada, dividin do-se o número de panículas pelo nümero de frutos.

A superfície lateral (SL) baseia-se na fórmula $S L=\pi(R+r) \sqrt{(R-r)^{2}+h^{2}}$, onde, $\pi=3,1416 ; h=$ altura; $R=$ raio inferior; $r=$ raio superior $e$ o indice de frutificaça $\vec{e}$ 
obtido dividindo-se o número de frutos pela superfície lateral.

A classificação das variedades segundo AVILĀN e FIGUeroA (1982) de acordo com a idade da planta e nível de e ficiência, foi o compreendido no período de plena produção como segue: $>6$, alto; 6-4, médio e <4, baixo.

\subsection{ANÁLISE ESTATÍSTICA}

Os dados foram submetidos a análise estatística para modelos não balanceados, empregando-se o programa LSMLGP (Least-squares, Maximum Likelinood General Purpose") de llarvey, citado por BARBIN (1977). E um programa bastante flexível, dan do opção do uso do "Processo de Absorção" empregado no ajusta mento de Somas de Quadrados. Para a anảlise estatística, o nümero de frutos foram transformados para $\sqrt{x}$, enquanto os outros parâmetros foram analisados sem transformação.

A comparação das médias de copas e/ou porte - en xertos foi feita através do teste de Tukey, ao nível de 5\% de probabilidade. 


\section{RESULTADOS E DISCUSSÃO}

\subsection{VEGETACÃO, FLORESCIMENTO E FRUTIFICAÇ̃̃O}

Durante os 3 anos de condução do experimento, foi observado que a maior floração correspondeu ao período de junho a agosto, o que concorda com SIMAO (1960), RODRIGUES et alii (1977) e SILVA (1982). Em condições de Hemisfério Norte, RUEHLLE e LEDIN (1955), observaram resultados semelhantes aos obtidos no presente experimento, pois o período de maior florescimento aconteceu nos meses de dezembro a março, correspondentes ao inverno.

A Tabela 1, mostra a média da produção de panículas e frutos e a percentagem de vegetação durante os anos de 1981, 1982 e 1983. 
Tabela 1 - Nümero médio de panículas e frutos e percentagem de vegetação observadas nos anos de 1981, 82 e 83, por planta en 7 porta-enxer tos com 5 repetições. ESALQ/USP, Piracicaba, SP.

\begin{tabular}{|c|c|c|c|c|c|}
\hline \multirow{2}{*}{ Copas } & \multirow{2}{*}{$\begin{array}{l}: \text { de vege } \\
\text { tação }\end{array}$} & \multicolumn{2}{|c|}{ Nümero } & \multirow{2}{*}{$\begin{array}{l}: \text { de } \\
\text { frutos }\end{array}$} & \multirow{2}{*}{$\begin{array}{c}\text { Relação } \\
\text { panícula } \\
\text { fruto }\end{array}$} \\
\hline & & Panículas & Frutos & & \\
\hline
\end{tabular}

1981:

$\begin{array}{lrrrrr}\text { Extrema } & 12,5 & 455,7 & 298,2 & 65,4 & 1,5 \\ \text { Imperial } & 12,2 & 383,6 & 340,3 & 88,7 & 1,1 \\ \text { Oliveira Neto } & 3,7 & 466,4 & 502,4 & 107,7 & 0,9 \\ \text { Carlota } & 5,6 & 479,4 & 590,1 & 123,1 & 0,8 \\ \text { Bourbon } & 1,8 & 597,9 & 443,9 & 74,2 & 1,3\end{array}$

1982:

$\begin{array}{lrrrrr}\text { Extrema } & 13,5 & 275,8 & 62,1 & 22,5 & 4,4 \\ \text { Imperial } & 22,1 & 397,9 & 82,2 & 20,6 & 4,8 \\ \text { Oliveira Neto } & 36,1 & 243,8 & 58,0 & 23,8 & 4,2 \\ \text { Carlota } & 6,7 & 214,7 & 63,7 & 29,7 & 3,4 \\ \text { Bourbon } & 37,0 & 308,9 & 40,8 & 13,2 & 7,6\end{array}$

1983:

\begin{tabular}{lrrrrr} 
Extrema & 11,1 & 981,3 & 185,5 & 18,9 & 5,3 \\
Imperial & 7,0 & 1067,9 & 26,5 & 2,5 & 40,3 \\
Oliveira Neto & 2,5 & 1056,8 & 137,5 & 13,0 & 7,7 \\
Carlota & 19,8 & 929,7 & 123,7 & 13,3 & 7,5 \\
Bourbon & 4,3 & 1057,7 & 4,3 & 0,4 & 245,9 \\
\hline
\end{tabular}


No ano de 1981 , houve uma tendência de grande fixação de frutos por panícula, talvez devido às condições de bai - xa precipitação ocorridas, principalmente nos meses de junho e agosto (Figura 1). Pois segundo SIMĀO (1960), dos elementos climáticos, a chuva $\bar{e}$ o mais desfavorável à frutifi cação. A baixa umidade relativa do ar, tambëm deve ter colaborado para a boa fixação de frutos, pois segundo PRATES e CAMPOS (1978), a umidade elevada, prejudica a poliniza ção e favorece a disseminação de doenças. De acordo com SIMÁo (1960), a principal doença que ocorre durante o período de f1o rescimento, nas condiçōes de Piracicaba, é o oídio (oidium man giferae Berthet). Segundo BUELL e HONS (1954), essa doença encontra condições favoráveis para o seu desenvolvimento nas temperaturas entre 15 e $22^{\circ} \mathrm{C}$. Como se observa na Figura 2 , em 1981, a temperatura no início da floração (junho e julho), $a=$ presentou-se próxima do limite inferior da faixa favorável ao desenvolvimento do oídio, além de que a precipitação foi menor que nos outros anos, podendo esses fatores terem contribuido para a menor incidência da doença neste ano e como consequên cia, uma maior produção de frutos.

Apesar da temperatura durante os meses de junho a agosto de 1982 , ter sido favorável ao florescimento e frutificação; as mangueiras apresentaram uma abundante vegetação e uma baixa produção de panículas e frutos, provavelmente, devido às maiores precipitações nesse período que prejudicam a polinização. Esses resultados concordam com BUELL e HONS (1964); 


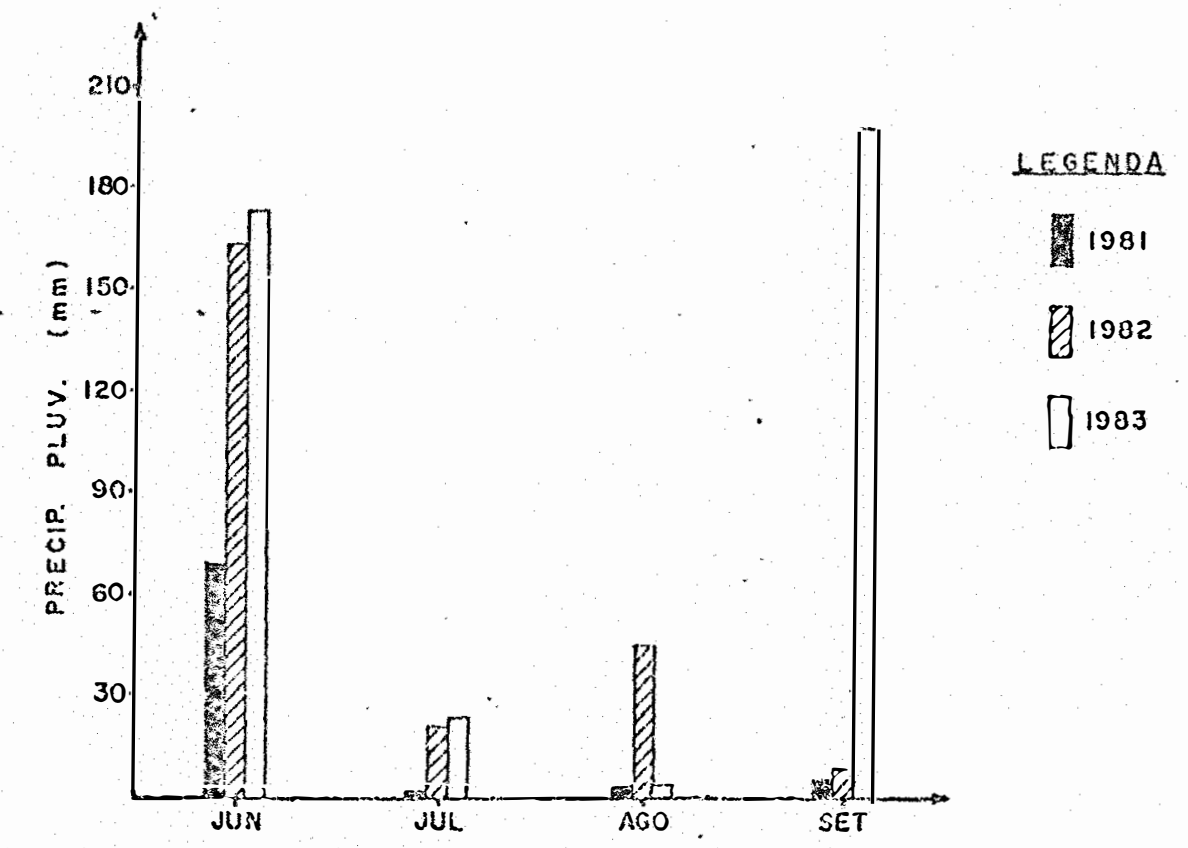

Figura 1 - Precipitação pluviomëtrica durante o período de florescimento da mangueira em Piracicaba nos anos de 1981, 1982 e 1983.

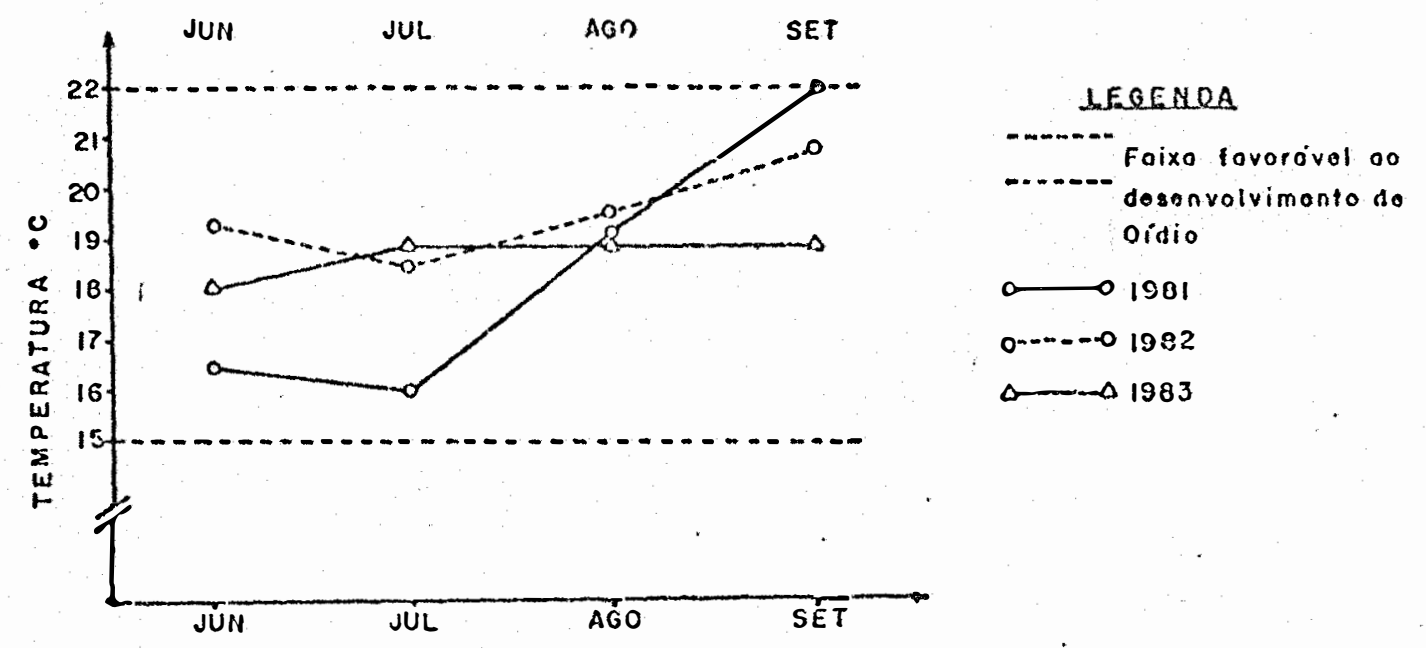

Figura 2 - Temperatura durante o período de flo rescimento de mangueira em Piracicaba nos anos de 1981, 1982 e 1983. 
SIMÃO (1960); MARANGA (1980); MANICA (1981) e SILVA (1982).

De acordo com a Tabela 1, em 1983, houve uma a 1 ta reiação panícula/fruto, como consequência de baixa produti$v i d a d e$ no ano de 1982 , que pode ter proporcionado um maior ac $\underline{u}$ mulo de nutrientes para a safra de 1983. De acordo com AVILĀN (1971) e MANICA (1981), durante o ciclo de produção existe uma alternância na frutificação, decorrente da variação dos nîveis de nutrientes. Essa alta relação panícula/fruto em 1983, pode ter sido causada também pela baixa viabilidade das flores a qual pode ter sido causada devido: a polinização das flores da mangueira ser muito deficiente (LYNCH e MUSTARD, 1955), a bai xa frutificaça a tribuida a pequena eficiência dos agentes polinizadores (SIMAO e MARANHXO, 1959; SINGH, 1960b e SINGH, 1964) e a existência de fiores não suscetiveis de frutificação e a queda de frutos muitos pequenos, atribuidos e causas mecânicas por agentes atmosféricos (LUTz, 1926). Pode-se ainda consi derar como um fator que contribuiu para esta alta relação paní cula/fruto, a possível ocorrência do oídio porque a temperatura nesse periodo situou-se na parte mediana de faixa favorävel para desenvolvimento do fungo (Figura 2).

Na Tabela 2 pode-se verificar através do índice de frutificação, que todos os tratamentos, com exceção da ' Carlota ' como copa, apresentaram baixo indice, de acordo com a claṣsificação de AVILAN (1980). Os melhores indáces de frutificação foram obtidos pela copa 'Carlota' scbre 'Oliveira Neto'. Essa copa sobre os demais porta-enxertos apre sentaram um indice médio. 
Tabela 2 - Altura, raio, superfície lateral, nümero de Exutos e índice de frutificação de mangueiras com 15 anos de idade.

\begin{tabular}{|c|c|c|c|c|c|c|c|}
\hline \multicolumn{2}{|c|}{ Variedades } & \multirow{2}{*}{$\begin{array}{l}\text { Altura } \\
\text { do cone } \\
{ }^{\prime} \mathrm{h}^{m}(\mathrm{~m})\end{array}$} & \multirow{2}{*}{$\begin{array}{l}\text { Raio } \\
\text { inferior } \\
\text { "R" (m) }\end{array}$} & \multirow{2}{*}{$\begin{array}{l}\text { Raio } \\
\text { superior } \\
\text { "r" (m) }\end{array}$} & \multirow{2}{*}{$\begin{array}{l}\text { Superfi- } \\
\text { la teral } \\
(\mathrm{SL})\left(\mathrm{m}^{2}\right)\end{array}$} & \multirow{2}{*}{$\begin{array}{l}\text { Nọ de } \\
\text { frutos }\end{array}$} & \multirow{2}{*}{$\begin{array}{l}\text { Indice } \\
\text { de fruti } \\
\text { ficação } \\
\left(\mathrm{N} O \mathrm{~F} / \mathrm{m}^{2}\right)\end{array}$} \\
\hline Copa & $\begin{array}{l}\text { Porta- } \\
\text {-enxerto }\end{array}$ & & & & & & \\
\hline Extrema & $\begin{array}{l}\text { Espada } \\
\text { Extrema } \\
\text { O1. Neto } \\
\text { Carlota } \\
\text { Coco } \\
\text { Pahiri }\end{array}$ & $\begin{array}{l}6,88 \\
6,80 \\
6,21 \\
7,01 \\
7,45 \\
6,96\end{array}$ & $\begin{array}{l}4,87 \\
5,04 \\
4,64 \\
4,78 \\
4,70 \\
4,85\end{array}$ & $\begin{array}{l}2,73 \\
2,82 \\
2,60 \\
2,68 \\
2,63 \\
2,72\end{array}$ & $\begin{array}{l}172,03 \\
176,63 \\
148,67 \\
171,50 \\
178,06 \\
173,10\end{array}$ & $\begin{array}{l}309,6 \\
296 \\
354,8 \\
251 \\
345,2 \\
340\end{array}$ & $\begin{array}{ll}1,8 & \mathrm{~B} \\
1,7 & \mathrm{~B} \\
2,4 & \mathrm{~B} \\
1,5 & \mathrm{~B} \\
1,9 & \mathrm{~B} \\
2,0 & \mathrm{~B}\end{array}$ \\
\hline $\begin{array}{l}\text { Impe- } \\
\text { rial }\end{array}$ & $\begin{array}{l}\text { Espada } \\
\text { Extrema } \\
\text { O1. Neto } \\
\text { Carlota } \\
\text { Coco } \\
\text { Pahiri }\end{array}$ & $\begin{array}{l}4,92 \\
5,59 \\
4,53 \\
-5,29 \\
5,25 \\
5,45\end{array}$ & $\begin{array}{l}4,48 \\
4,82 \\
4,05 \\
4,58 \\
4,57 \\
4,41\end{array}$ & $\begin{array}{l}2,51 \\
2,70 \\
2,27 \\
2,56 \\
2,56 \\
2,47\end{array}$ & $\begin{array}{r}116,38 \\
141,24 \\
96,64 \\
127,02 \\
126,92 \\
125,03\end{array}$ & $\begin{array}{l}368 \\
300,2 \\
299,2 \\
352,8 \\
420,4 \\
374,8\end{array}$ & $\begin{array}{ll}3,2 & \mathrm{~B} \\
2,1 & \mathrm{~B} \\
3,1 & \mathrm{~B} \\
2,8 & \mathrm{~B} \\
3,3 & \mathrm{~B} \\
3,0 & \mathrm{~B}\end{array}$ \\
\hline $\begin{array}{l}\text { Oliv. } \\
\text { Neto }\end{array}$ & $\begin{array}{l}\text { Espada } \\
\text { Extrema } \\
\text { 01. Neto } \\
\text { Carlota } \\
\text { Coco } \\
\text { Pahiri }\end{array}$ & $\begin{array}{l}6,86 \\
6,86 \\
6,38 \\
6,12 \\
6,88 \\
6,55\end{array}$ & $\begin{array}{l}5,31 \\
5,00 \\
4,99 \\
4,55 \\
5,08 \\
4,84\end{array}$ & $\begin{array}{l}2,97 \\
2,80 \\
2,79 \\
2,55 \\
2,84 \\
2,71\end{array}$ & $\begin{array}{l}188,54 \\
176,53 \\
164,95 \\
143,61 \\
180,03 \\
163,37\end{array}$ & $\begin{array}{l}555,6 \\
554,2 \\
526,2 \\
460 \\
489,8 \\
475,8\end{array}$ & $\begin{array}{ll}2,9 & \mathrm{~B} \\
3,1 & \mathrm{~B} \\
3,2 & \mathrm{~B} \\
3,2 & \mathrm{~B} \\
2,7 & \mathrm{~B} \\
2,9 & \mathrm{~B}\end{array}$ \\
\hline Carlota & $\begin{array}{l}\text { Espada } \\
\text { Extrema } \\
\text { O1. Neto } \\
\text { Carlota } \\
\text { Coco } \\
\text { Pahiri }\end{array}$ & $\begin{array}{l}5,00 \\
5,37 \\
5,02 \\
5,05 \\
4,47 \\
5,16\end{array}$ & $\begin{array}{l}4,50 \\
4,45 \\
4,06 \\
4,32 \\
3,89 \\
4,25\end{array}$ & $\begin{array}{l}2,52 \\
2,49 \\
2,27 \\
2,42 \\
2,18 \\
2,38\end{array}$ & $\begin{array}{r}118,60 \\
124,63 \\
105,98 \\
114,25 \\
91,26 \\
114,32\end{array}$ & $\begin{array}{l}655,7 \\
582,8 \\
677,8 \\
717,7 \\
495,4 \\
615,7\end{array}$ & $\begin{array}{l}5,5 \mathrm{M} \\
4,7 \mathrm{M} \\
6,4 \mathrm{~A} \\
6,3 \mathrm{~A} \\
5,4 \mathrm{M} \\
4,3 \mathrm{M}\end{array}$ \\
\hline Bourbon & $\begin{array}{l}\text { Espada } \\
\text { Extrema } \\
\text { 01. Neto } \\
\text { Carlota } \\
\text { Coco } \\
\text { Pahiri }\end{array}$ & $\begin{array}{l}6,41 \\
6,37 \\
6,27 \\
8,87 \\
6,27 \\
6,68\end{array}$ & $\begin{array}{l}4,73 \\
4,43 \\
4,58 \\
4,40 \\
4,18 \\
4,81\end{array}$ & $\begin{array}{l}2,65 \\
2,48 \\
2,56 \\
2,46 \\
2,34 \\
2,69\end{array}$ & $\begin{array}{l}156,24 \\
144,62 \\
147,76 \\
195,68 \\
133,84 \\
165,13\end{array}$ & $\begin{array}{l}514,8 \\
405 \\
489,6 \\
411,2 \\
420,8 \\
477,4\end{array}$ & $\begin{array}{ll}3,3 & \mathrm{~B} \\
2,8 & \mathrm{~B} \\
3,3 & \mathrm{~B} \\
2,1 & \mathrm{~B} \\
3,1 & \mathrm{~B} \\
3,0 & \mathrm{~B}\end{array}$ \\
\hline
\end{tabular}

* $\mathrm{B}=$ baixo; $\mathrm{M}=$ médio; $\mathrm{A}=$ alto. 


\subsection{AltURA. E DiÂMETRO DAS COPAS}

No tratamento em que foi utilizado a ivariedade Pahiri como copa, sobre todos os porta-enxertos, apresentou uma grande quantidade de plantas mortas, correspondendo a $51,4 \%$ do total. Da mesma forma, quando se usou a variedade Bourbon como porta-enxerto, houve uma mortalidade muito grande das plan tas $(43,3 \%$ do tota 1$)$, tendo sido por este motivo, eliminados esses tratamentos para efeito de anälise estatística.

Os dados de altura de copa da Tabela 3, durante o ano de 1981, analisados pelo mëtodo descrito no item 3,7., a presentou teste F significativo ao nível de 1\% de probabilidade, para copas e significativo ao nível de 5\% de probabilidacie para porta-enxertos; não houve significância para a interašão co pas $x$ porta-enxertos.

Tabela 3 - Anālise de variância para altura de copa do ano de 1981.

\begin{tabular}{lrrrc}
\hline Causas de variação & G.L. & SQ & QM & F \\
\hline Blocos & 4 & 0,5721 & $\bullet, 1430$ & - \\
Copa (C) & 4 & 85,4444 & 21,3611 & $40,37^{\star *}$ \\
Resíduo (a) & 16 & 8,4656 & 0,5291 & \\
\hline Porta-enxerto (P) & 5 & 0,9489 & 0,9489 & $2,37^{\star}$ \\
Interação C x P & 20 & 0,3994 & 0,3994 & $0,996 \mathrm{~ns}$ \\
Resíduo (b) & 86 & 34,4836 & 0,4010 & \\
\hline$\hat{\mathrm{m}}=6,1279$ & & & & \\
C.V $\cdot \mathrm{a}=11,87^{\circ}$ & & & & \\
C.V.b $=10,33^{\circ}$ & & & & \\
\hline
\end{tabular}


A comparação das médias, pelo teste Tukey (Tabe 1a 4) mostrou que as copas das variedades Extrema, Oliveira Ne to e Bourbon, não diferiram entre si e diferiram, estatisticamente, ao nível de 5\% de probabilidade, das variedades Imperial. e Carlota.

Tabela 4 - Teste de Tukey para as médias de altura de copa, das copas.

\begin{tabular}{lcc}
\hline Variedades & Mëdia & Tukey $(5 \%)$ \\
\hline Extrema & 6,984 & $\mathrm{a}$ \\
Oliveira Neto & 6,785 & $\mathrm{a}$ \\
Bourbon & 6,460 & $\mathrm{a}$ \\
Inperial & 5,224 & $\mathrm{~b}$ \\
Carlota & 5,066 & $\mathrm{~b}$ \\
\hline
\end{tabular}

Na comparação das médias do porta-enxerto (Tabe la 5), só houve diferença entre Pahiri e Oliveira Neto, ao nível de $5 \%$ de probabilidade.

Tabela 5 - Teste de Tukey para as médias de alturas de copas (m) clos porta-enxertos.

\begin{tabular}{lll}
\hline Variedades & Média & Tukey $(5 \%)$ \\
\hline Pahiri & 6,350 & $\mathrm{a}$ \\
Extrema & 6,316 & $\mathrm{ab}$ \\
Coco & 6,206 & $\mathrm{ab}$ \\
Espada & 6,126 & $\mathrm{ab}$ \\
Carlota & 6,018 & $\mathrm{ab}$ \\
Oliveira Neto & 5,784 & $\mathrm{~b}$
\end{tabular}


O diâmetro da copa, apresentou teste F significativo ao nível de $1 \%$ de probabilidade para as copas, entretan to, não houve significância para porta-enxertos e interação co pa $x$ porta-enxertos (Tabela 6).

Tabela 6 - Diâmetro da copa do ano de 1981.

\begin{tabular}{lrrrr} 
Causas de variação & G.L. & SQ & QM & F \\
\hline Blocos & 4 & 1,5965 & 0,3991 & \\
Copas (C) & 4 & 40,6119 & 10,1530 & $7,21^{* *}$ \\
Resíduo (a) & 16 & 22,5401 & 1,4087 & \\
\hline Porta-enxertos (P) & 5 & 6,8917 & 1,3783 & $1,80 \mathrm{~ns}$ \\
Interação C x P & 20 & 14,9683 & 0,7484 & $0,976 \mathrm{~ns}$ \\
Resíduo (b) & 86 & 65,9218 & 0,7665 & \\
\hline m $=9,1985$ & & & & \\
C.V $\cdot a=12,90^{\circ}$ & & & & \\
C. $._{b}=9,52^{\circ}$ & & & & \\
\hline
\end{tabular}

A comparação das médias pelo teste de Tukey (Taㅡ bela 7), mostrou que as copas das variedades OIiveira Neto, E E trema e Bourbon, não diferiram entre si mas, a primeira dife- 
riu, estatisticamente, ao nível de 5\% de probabilidade de Impe rial e Carlota, enquanto Extrema diferiu de Carlota.

Tabela 7 - Teste de Tukey para as médias de diâmetro da copa (m) das copas.

\begin{tabular}{lcc}
\hline Variedades & Médias & Tukey $\left(5^{\circ}\right)$ \\
\hline Oliveira Neto & 9,9923 & $\mathrm{a}$ \\
Extrema & 9,6423 & $\mathrm{ab}$ \\
Bourbon & 9,0466 & $\mathrm{abc}$ \\
Imperial & 8,8480 & $\mathrm{bc}$ \\
Carlota & 8,4636 & $\mathrm{c}$ \\
\hline
\end{tabular}

Como se observa, os dados de diâmetro e altura de copa nas variedades Oliveira Neto, Extrema e Bourbon foram maiores que para as outras variedades (Tabelas 4 e 7 ), indicando isto, maior desenvolvimento vegetativo até 1981 .

\subsection{NÚMERO DE FRUTOS}

Os dados de número de frutos (Tabela 8), para o ano de 1981, apresentou teste F significativo ao nível de 1\% de probabilidade para as copas, entretanto, não houve significância para porta-enxertos e interação copa $x$ porta-enxertos. 
Tabela 8 - Nünero de frutos do ano de 1981.

\begin{tabular}{lrrrr}
\hline Causas de variação & G.L. & SQ & QM & F \\
\hline Blocos & 4 & 250,1243 & 62,5311 & 3,91 \\
Copas (C) & 4 & 815,4918 & 203,8729 & $12,74^{* *}$ \\
Resíduo (a) & 16 & 256,1308 & 16,0082 & \\
\hline Porta-enxertos (P) & 5 & 22,7195 & 4,5439 & $0,922 \mathrm{~ns}$ \\
Interação C x P & 20 & 123,5272 & 6,1763 & $1,25 \mathrm{~ns}$ \\
Resíduo (b) & 86 & 423,5842 & 4,9254 & \\
\hline$\hat{\mathrm{m}}=20,9869$ & & & & \\
C.V. ${ }^{\mathrm{a}}=19,06^{\circ}$ & & & & \\
C.V ${ }_{b}=10,57^{\circ}$ & & & & \\
\end{tabular}

A comparação das médias pelo teste de Tukey ao nível de 5\% de probabilidade (Tabela 9), mostram que as variedades que mais produziram frutos foram Carlota e Oliveira $\mathrm{Ne}-$ to. Entretanto, SIMAO (1960) relata que Carlota foi uma das me nos produtivas entre 12 variedades estudadas. 
Tabela 9 - Teste de Tukey para as médias de nümero de frutos das copas do ano de 1981.

\begin{tabular}{|c|c|c|}
\hline Variedades & Médias & Tukey $(5 \%)$ \\
\hline Carlota & 24,49 & $\mathrm{a}$ \\
\hline Oliveira Neto & 22,40 & $a b$ \\
\hline Bourbon & 21,10 & bc \\
\hline Imperial & 18,66 & $\mathrm{~cd}$ \\
\hline Extrema & 17,66 & $d$ \\
\hline
\end{tabular}

No ano de 1982 não houve significância para efeito de copa na produção de frutos (Tabela 10), entretanto, o teste F foi significativo ao nivel de 1\% de probabilidade para porta-enxertos; não houve significância para a interação copax x porta-enxertos.

Tabela 10 - Número de frutos do ano de 1982.

\begin{tabular}{lcccc}
\hline Causas de variação & G.L. & SQ & QM & F \\
\hline Blocos & 4 & 415,6170 & 103,9042 & \\
Copas (C) & 4 & 46,4522 & 22,6130 & 0,181 ns \\
Resíduo (a) & 16 & 1025,9626 & 64,1227 & \\
\hline Porta-enxerto (P) & 5 & 432,1887 & 86,4377 & $5,20 * *$ \\
Interação C x P & 20 & 263,6946 & 13,1847 & 0,793 ns \\
Resíduo (b) & 94 & 1562,2976 & 16,6202 & \\
\hline$\hat{\mathrm{m}}=5,9777$ & & & & \\
C.V. $=133,96 \%$ \\
C.V. $\cdot b=68,20 \%$
\end{tabular}


0 teste de Tukey para as médias do nümero de fru tos para o ano de 1982 (Tabela 11), mostra que o melhor porta-enxerto foi 'Carlota', 'Extrema', 'Oliveira Neto' e 'Pahiri'.

Tabela 11 - Teste de Tukey para as médias de nümero de frutos das variedades de porta-enxerto para o ano de 1982.

\begin{tabular}{lll} 
Variedades & Médias & Tukey (5\%) \\
\hline Carlota & 7,97 & a \\
Extrema & 7,08 & ab \\
Oliveira Neto & 6,68 & ab \\
Pahiri & 5,02 & abc \\
Coco & 3,98 & bc \\
Espada & 3,21 & c
\end{tabular}

De acordo com SIMAOO (1960), as variedades Extre ma e Pahiri, são muito suscetíveis a oídio; no presente experi mento, essas variedades não diferiram estatisticamente ao nível de 5\% de probabilidade, das variedades Carlota e 0liveira Neto que segundo aquele autor, são pouco suscetíveis a doença, e que provavelmente este carāter, seja transferido do porta-enxerto para a copa através da enxertia.

A anälise de variância do número de frutos do $\underline{a}$ no de 1983 (Tabela 12), indicou resultado semelhante ao do ano de 1981 . 
Tabela 12 - Nứnero de frutos do ano de 1983.

\begin{tabular}{|c|c|c|c|c|}
\hline Causas de variação & G.L. & $S Q$ & $\mathrm{QM}$ & $\mathrm{F}$ \\
\hline Blocos & 4 & 216,4910 & 54,1227 & \\
\hline Copas (C) & 4 & 2771,8130 & 692,9532 & $24,64^{* *}$ \\
\hline Resíduo (a) & 16 & 450,0422 & 28,1276 & \\
\hline Porta-enxertos (P) & 5 & 3,7943 & 0,7588 & $0,150 \mathrm{~ns}$ \\
\hline Interação C x P & 20 & 94,9247 & 4,7462 & $0,655 \mathrm{~ns}$ \\
\hline Resíduo (b) & 91 & 659,1490 & 7,2434 & \\
\hline \multicolumn{5}{|l|}{$\hat{\mathrm{m}}=8,5509$} \\
\hline \multicolumn{5}{|l|}{$\mathrm{C} \cdot \mathrm{V}_{\mathrm{a}_{\mathrm{a}}}=62,02^{\circ}$} \\
\hline \multicolumn{5}{|l|}{$C \cdot V_{\cdot b}=31,47^{\circ}$} \\
\hline \multicolumn{5}{|c|}{$\begin{array}{l}\text { Tabela } 13 \text { - Teste de Tukey para as médias de número de frutos das varieda } \\
\text { des de copas para o ano de } 1983 \text {. }\end{array}$} \\
\hline Variedades & Médias & Tukey & $5 \%)$ & \\
\hline Extrema & 13,44 & $\mathrm{a}$ & & \\
\hline Oliveira Neto & 11,90 & $\mathrm{a}$ & & \\
\hline Carlota & 10,81 & $\mathrm{a}$ & & \\
\hline Imperial & 4,90 & $\mathrm{~b}$ & & \\
\hline Bourbon & 1,93 & $\mathrm{~b}$ & & \\
\hline
\end{tabular}


As médias do nümero de frutos comparadas atravës do teste de Tukey ao nível de 5\% de probabilidade para o a no de 1983, mostraram um resultado semelhante áo do ano de 1981 quánto as variedades mais produtivas, com exceção da 'Extrema' que revelou como uma das mais produtivas, devido talvez a menor incidência de oídio (Tabela 13). 


\section{CONCLUSÕES}

De acordo com as observações no período deste trabalho os resultados obtidos permitem tirar as seguintes con clusōes:

1. As copas mais produtivas foram 'Carlota' e 'Oliveira Neto'.

2. Os porta-enxertos que influenciaram maior produção foram 'Carlota' e 'Oliveira Neto'.

3. Os dados de diâmetro e altura de copa nas variedades 0live ra Neto, Extrema e Bourbon foram maiores que para as outras variedades, indicando isto, maior desenvolvimento vege tativo. 
4. O desenvolvimento da copa em altura e em diâmetro estâ 1iga do a variedade da copa.

5. A variedade Pahiri quando utilizada como copa apresenta mor talidade muito alta o mesmo acontecendo com a Bourbon quando utilizada como porta-enxerto. 


\section{LITERATURA CITADA}

AVILAN, L., 1971. Variaciones de los niveles de nitrogeno, fósforo, potasio y calcio en las hojas de mango (Mangifera indica L.) através de un ciclo de producción. Agronomía Tropical. Maracay, Venezuela, 21(1): 3-10.

AVILAN, L., 1980. El "indice de fructificación" en frutales perennes. Agronomia Tropical. Maracay, 30(1-6): 147-157.

AVILĀN, L.; M. FIGUEROA e G. LABOREM, 1981. Consideraciones acerca de los sistemas de plantación en Mango. Fruits. Paris, $\underline{36}(3): 171-179$.

AUBERT, B., 1975. Possibilites de production de mangues greffes a 1a Reunion. Fruits. Paris, 30(7-8): 447-479. 
AUBERT, B. e P. LOSSOIS, 1972. Considerations sur la phenologie des species fruitieres arbustives. Fruits. Paris, $\underline{27}(t)$ : 269-286.

BARBIN, D., 1977. Aspectos estatísticos de alguns modelos matemáticos usados no melhoramento do gado de corte. Piracicaba, ESALQ/USP, 110p. [Tese de Livre Docente].

BARNELL, E., 1939. Studies in Tropical Fruits. Annais of Botany, 3 : $77-89$.

BRUNINI, O. e R.R. ALFONSI, 1980. Aptidão ecológica para a mangueira. Anais do I Simpósio Brasileiro sobre a cultura da mangueira. Jaboticabal, SP, p.23-33.

BUCKLEW, L.L., 1957. My experience with the mango in California. Proceedings of the Florida. Mango Forum. p.13-15.

BUELL, E.P., 1954. Flowering and fruiting habits of the mango in the Wet Zone. Tropical Agriculturist. Paradeniya, Cei1 ão, $110(4): 280-284$.

BUEHL, E.P. A B.A. HONS, 1954. Flowering and fruiting in the Wet Zone. Tropical Agriculturist. Paradeniya, Ceilão, 110: $280-284$. 
CAMARGO, A.P.; M.J. PEDRO Jr.; O. BRUNINI; R.R. ALFONSI; A.A. ORTOLANI e H.S. PINTO, 1977. Zoneamento Agricola do Estado de São Paulo, Aptidão Climática. Secretaria do Estado de São Paulo, 2: $131 \mathrm{p}$.

COBIN, M., 1950. The present outlock of the mango in Florida. Avocado Society - Yearbook. Texas, p.60-70.

DE CANDOLLE, A., 1959. Origin of cultivated plants. 2a ed. New York, Hafner Publ. 468p.

DONI, M.E., 1974. Florescimento e frutificação da mangueira (Mangifera indica L.) variedade Haden. ESALQ/USP, Piracicaba, SP, 51p. [Dissertação de Mestrado] .

FAO - Production Yearbook, 1981. Rome, 35: 306. [Fao Statistics series, 40$\}$.

GAILLARD, J.P., 1978. Etudes sur les fruitier tropicaux. Fruits. Paris, $33(9): 543-665$.

GARDNER, V.R.; F.C. BRADFORD e H.D. HOOKER, 1927. Orcharding. The Maple Press Co., New York. 331p.

IBGE, 1982. Anuário Estatístico do Brasil, Rio de Janeiro, $837 \mathrm{p}$. 
ITAL, 1981. Frutas tropicais - Manga. Governo do Estado de São Paulo, Secretaria de Agricultura e Abastecimento - Coordenadoria da Pesquisa Agropecuäria, $\underline{8}: 399 \mathrm{p}$.

JAWANDA, J.S. e K.K. SINGH, 1961. Floral biology and fruit drop in some mango varieties of Punjab. Indian Journal of Agriculture Science. New Delhi, 31(2): 81-91.

KENNARD, W.C. e J.L. SPENCER, 1956. Frankliniella sp. on mango. U.S. Dept. of Agriculture. Moyaguez, $4: 4$.

KNIGHT Jr., R.J., 1980. Situação mundial da mangicultura. A-nais do I Simpósio Brasileiro sobre a cultura da mangueira. Jaboticabal, SP. p.193-213.

LUTz, B., 1926. Estudos sobre a biologia floral da Mangifera indica L. Archivos do Museu Nacional do Rio de Janeiro. Rio de Janeiro, (26): 125-158.

LYNCH, S.J. e M.J. MUSTARD, 1955. Mango in Florida. Florida Department of Agriculture. Florida Bull., (20): 88 .

MALLIK, P.C., 1957. Morphology and biology of the mango flower. Indian Journal of Horticulture. Bengalore, India, 14(1): 1-23. Apud: Biological Abstract. Menasha, USA, 1958, 32 (9930). 
MANICA, I., 1981. Fruticultura Tropical. 2. Manga. Ed. Agronômica Ceres. São Paulo. $135 p$.

MARANCA, G., 1980. Fruticultura Comercial - Manga e Abacate. São Paulo, Livraria Nobel S/A, 138p.

MORAlES, E.A.U., 1971. As mangas que a Āsia nos deu. Cerrado. Brasilia, $\underline{3}(14): 22-25$.

NAKASONE, H.Y.; F.A.I. BOWERS e J.H. BEAUMONT, 1955. Terminal growth and flowering behaviour of the Pirie mango in Hawaii. Proceeding of the American Society for Horticultural Science. St. Joseph - Michigan, 66: 183-191.

POPENOE, W., 1917. The pollination of the mango. United States Department of Agriculture. Bull, Washington, D.C., (542): 20 .

PRASAD, A. e R.A. PATAK, 1970. Biennial bearing of mango, Tropical Agriculturist. Paradeniya, Ceilão, 126: 35-56.

PRATES, H.S. e J.S. CAMPOS de, 1978. Cultura da mangueira. Boletim Técnico 120 - CATI, Campinas, SP, 10p.

RAMOS, V.H.V., 1982. Variedades de mangueira. Informa Agropecuário. Belo Horizonte, MG, $8(86):$ 11-20. 
RANZANI, G.; O. FREIRE e T. KINJO, 1966. Carta de Solos do Município de Piracicaba, Piracicaba, SP, $85 \mathrm{p}$.

ROY, R.S., 1953. Study of irregular bearing of mango. The Indian Journal of Agricultural Science. New Delhi, India, 10: $157-160$.

RODRIGUES, L., 1922. Porquai les manguiers ni fructifients ils pas. Revue de Botanique Appliquee et d'Agriculture Tropica1e. Paris, 2: 524 .

RODRIGUES, J.A.S.; R.V.R. PINHEIRO; I . MANICA; V.W.D. CASALI e A.R. CONDE, 1977. Comportamento de dez variedades de manga (Mangifera indica L.) em Viçosa e Visconde do Rio Branco, Minas Gerais. Revista Ceres, Viçosa, MG, 24(136): 580-595.

RUEHLE, G.D. e R.B. LEDIN, 1955. Mango growing in Florida. Florida Agricultural Experiment Station - Bull. Florida, 574: $90 \mathrm{p}$.

SAMPAIO, J.M.M., 1980. Características gerais de algumas cultivares e tipos de mangueiras no Brasil. Anais do I Simpósio Brasileiro sobre a cultura da mangueira. Jaboticabal, SP, $35-50$. 
SETZER, J., 1967. Atlas climático ecológico do Estado de São Paulo, Comissão Interestadual da Bacia Paraná - Uruguai CESP, São Paulo, 61p.

SEN, P.K., 1944. Irregular bearing of mango. Indian Farming. Bengalore, India, 5: 408-411.

SEN, P.K, e S.C. MAITI, 1969. Studies on biennial bearing in mango. I. Varietal difference in biennial intensity. II. Relation between growth flushes of shoots and flowering. Horticultural Science Calcutta, 1: 1-4, 43-53. Apud: Horticultural Abstract. East Mailing, Inglaterra, 1970 $40(7414)$.

SWAWKY, I.; Z. ZIDAN, 1978. Sex distribution, fruit set and fruiting of Zebda mango inflorescence. Annals of Agricultural Science. University of Ain Shan Egypt. Figito, 20(2): 159-166. Apud: Abstract on Tropical Agriculture. Amsterdã, 4 (20981).

SHAWKY, I.; Z. ZIDAN; A. EL-TOMI e D. DAHSHAN, 1980. Flowering malformation in relation to vegetative growth of "Taimour" mangoes. Egyptian Journal of Horticulture. Cairo, ? (1): 1-8. 
SILVA, W.J., 1982. Aptidão climática da cultura da mangueira. Informe Agropecuärio. Belo Horizonte, MG, $\underline{8}(86):$ 5-8.

SIMÃO, S., 1955. Contribuição para caracterização de algumas variedades de mangueira Mangifera indica L. ESALQ/USP, Piracicaba, SP, 96p. [Tese de Livre Docente].

SIMAO, S., 1956. Considerações sobre a caracterização de variedades de mangueira. 0 Solo. Piracicaba, SP, 1: 25-28.

SIMAOO, S., 1957. Cultura da mangueira. Lavoura e Criação. São Paulo, 95: 20-29.

SIMAOO, S., 1958. Causas que determinam a queda dos frutos. Coopercotia. São Paulo, 95: 33-34.

SJMAO, S., 1960. Estudos da planta e do fruto da mangueira (Mangifera indica L.). ESALQ/USP, Piracicaba, SP, 167p. [Tese para provimento de Cátedra].

SIMAO, S., 1968. Croissance et floraison du manguier dans l'eta de São Paulo (Brésil). Fruits d'outre mer. Paris, $23(7): 388-390$.

SIMAO, S., 1971. Manual de Fruticultura. São Paulo, Ed. Agronômica Ceres, 530p. 
SIMÃo, S., 1980a. Situação da cultura da mangueira no Brasil. Anais do I Simpósio Brasileiro sobre a cultura da mangueira. Jaboticabal, SP, 3-11.

SIMÃO, 1980b. Botânica e biologia da mangueira. Anais do I Simpósio Brasileiro sobre a cultura da mangueira. Jaboticabal, SP, 13-21.

SIMAO, S. e Z.C. MARANHAO, 1959. Agentes polinizadores da mangueira. Anais da ESALQ/USP, 16: 299-304.

SINGH, L.B., 1948. Studies in biennial bearing. Journal of Horticultural Science. London, 24: 45-65, 123-143.

SINGH, L.B., 1960. The Mango. New York Interscience Publishers, Inc., World Crops Books, New York, 438p.

SINGH, R.N., 1964. Sex pollination and post-fertilization. Problems in mango. World Crops. London, 16(4): 24-26.

SINGH, L.B., 1968. The niango, botany, cultivation and utilization. Leonard Hill Books Limited, London, 438p.

SINGH, L.B., 1975. Ecophysiology of mango. In: "Ecophysiology of Tropical Crops". Manaus, Brasil, 2: 7p. 
SPENCER, J.L. e W.C. KENNAKD, D., 1956. Limited stigmatic receptivity may contribute to low fruit set in the mango (Mangifera indica L.). Proceeding of the American Society for Horticultural Science. New York: 287-289.

WERNER, F.P., 1936. Mangas. Boletim de Agricultura, Zootecnia e Veterinária. Secretaria Agricultura Indūstria e Comércio e Trabalho. Minas Gerais, $\underline{3}$ : 185-188.

WOLFE, H.; E. OORDT; R. FIGUEROA e R. FRANCIOSI, 1969. El cultivo del mango en el Perú. Ministério de Agricultura y Pesqueria. Lima, Boletim Técnico. $74: 38 \mathrm{p}$.

WOLFENBARGER, D.0., 1957. Insects in relation to fruitest of mango. proceedings of the Florida. State Hortícultural Society. Lake Alfred, Florida, 11-13. 
.49 .

\section{APÊNDICE}




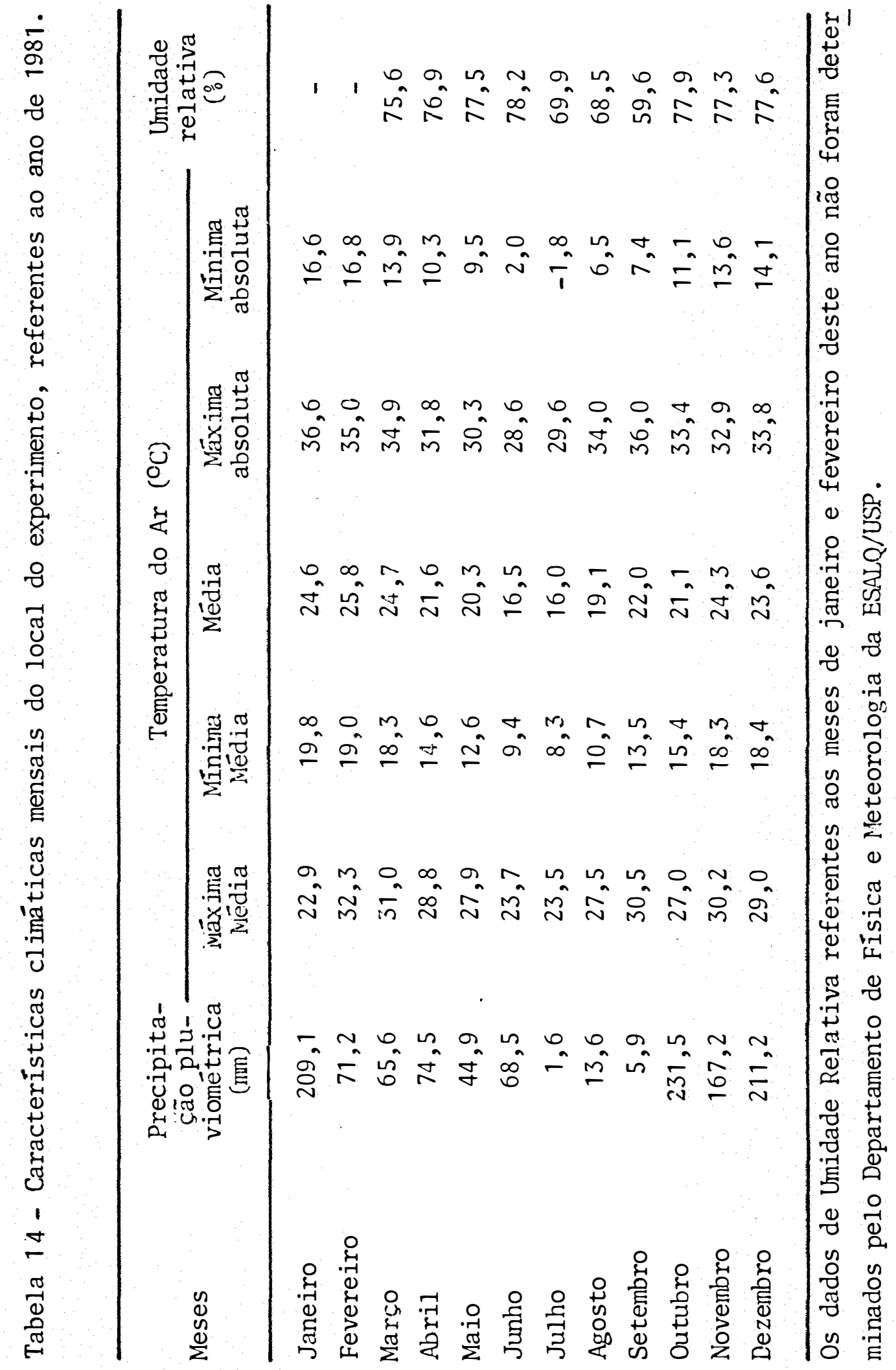




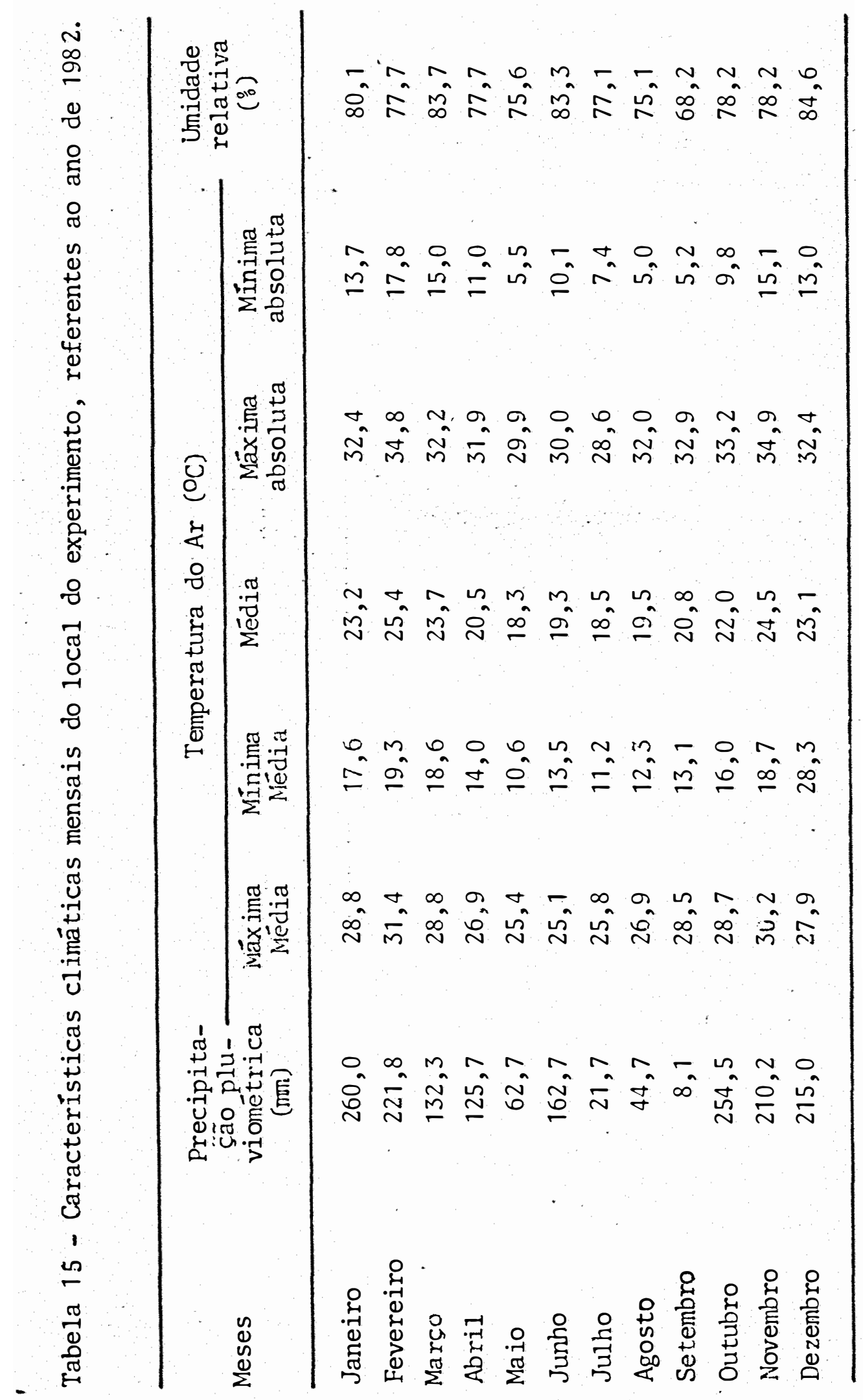




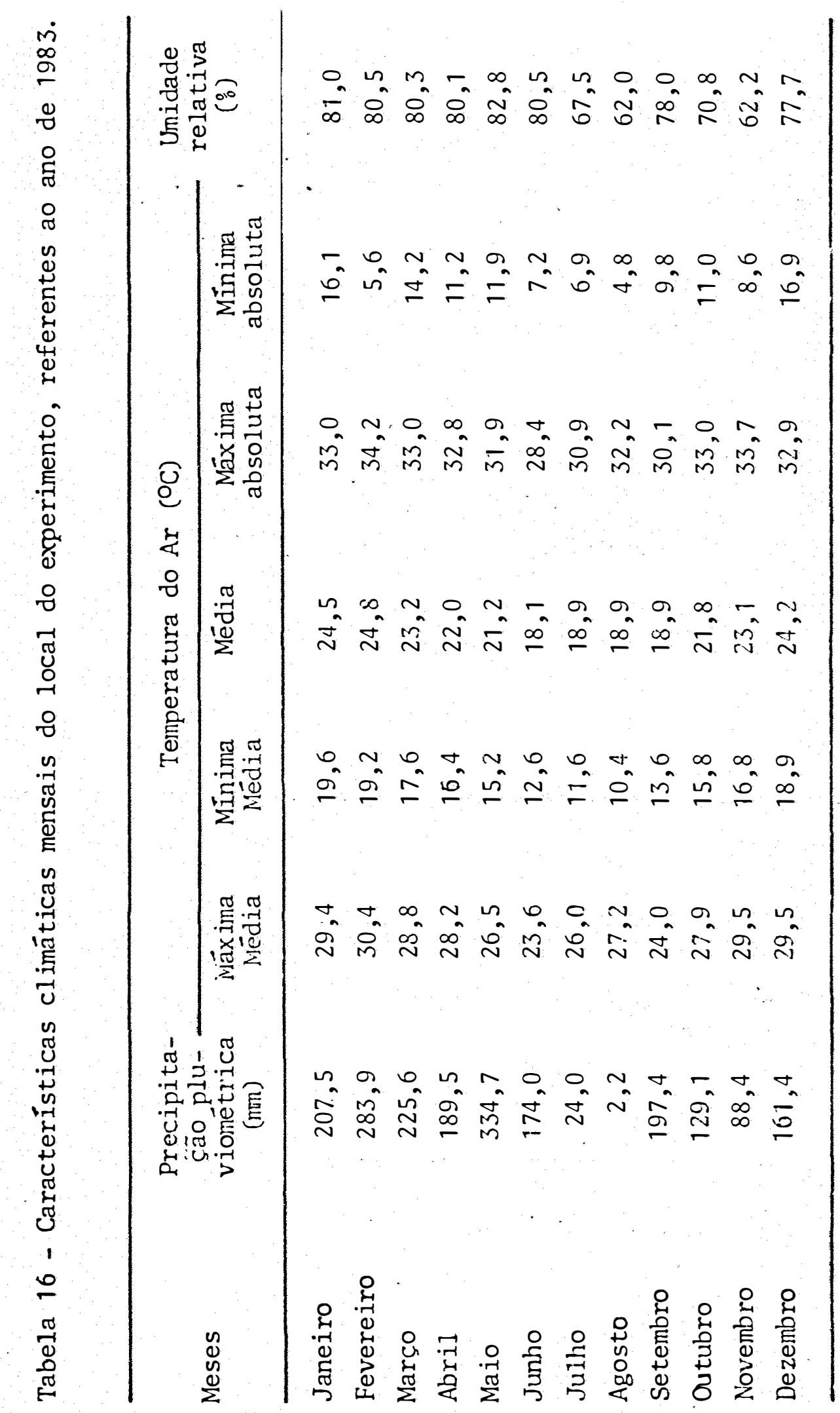


Tabela 17 - Altura (m) das copas de 5 variedades de mangueira sobre 6 dife rentes porta-enxertos, em Piracicaba, SP, em 1981.

\begin{tabular}{|c|c|c|c|c|c|c|c|}
\hline \multicolumn{2}{|c|}{ Tratamentos } & \multicolumn{5}{|c|}{ Repetições } & \multirow{2}{*}{ TOTAL } \\
\hline Copa & Porta-enxerto & I & II & III & IV & V & \\
\hline Extrema & $\begin{array}{l}\text { Espada } \\
\text { Extrema } \\
\text { Oliveira Neto } \\
\text { Carlota } \\
\text { Coco } \\
\text { Pahiri }\end{array}$ & $\begin{array}{l}7,60 \\
8,20 \\
6,30 \\
7,10 \\
8,00 \\
6,70\end{array}$ & $\begin{array}{l}7,50 \\
6,10 \\
6,10 \\
7,30 \\
7,40 \\
8,20\end{array}$ & $\begin{array}{l}6,50 \\
7,80 \\
6,00 \\
7,40 \\
7,60 \\
6,20\end{array}$ & $\begin{array}{l}6,70 \\
6,50 \\
6,10 \\
- \\
- \\
7,30\end{array}$ & $\begin{array}{l}6,80 \\
6,10 \\
7,10 \\
6,80 \\
7,40 \\
-\end{array}$ & $\begin{array}{l}35,10 \\
34,70 \\
31,70 \\
28,60 \\
30,40 \\
28,40\end{array}$ \\
\hline Imperial & $\begin{array}{l}\text { Espada } \\
\text { Extrema } \\
\text { Oliveira Neto } \\
\text { Carlota } \\
\text { Coco } \\
\text { Pahiri }\end{array}$ & $\begin{array}{l}5,60 \\
5,40 \\
4,50 \\
5,20 \\
5,20 \\
6,00\end{array}$ & $\begin{array}{l}4,50 \\
- \\
4,70 \\
5,60 \\
5,60 \\
5,40\end{array}$ & $\begin{array}{l}4,20 \\
5,80 \\
4,10 \\
5,60 \\
5,00 \\
5,00\end{array}$ & $\begin{array}{l}5,50 \\
6,00 \\
5,80 \\
5,60 \\
5,00 \\
6,00\end{array}$ & $\begin{array}{l}5,30 \\
5,60 \\
4,00 \\
5,00 \\
6,00 \\
5,40\end{array}$ & $\begin{array}{l}25,10 \\
22,80 \\
23,10 \\
27,00 \\
26,80 \\
27,80\end{array}$ \\
\hline $\begin{array}{l}\text { Olivei- } \\
\text { ra Neto }\end{array}$ & $\begin{array}{l}\text { Espada } \\
\text { Extrema } \\
\text { Oliveira Neto } \\
\text { Carlota } \\
\text { Coco } \\
\text { Pahiri }\end{array}$ & $\begin{array}{l}6,30 \\
7,50 \\
6,80 \\
6,60 \\
6,50 \\
7,30\end{array}$ & $\begin{array}{l}7,80 \\
6,50 \\
6,50 \\
5,60 \\
7,20 \\
7,40\end{array}$ & $\begin{array}{l}6,70 \\
7,20 \\
7,30 \\
- \\
7,80 \\
5,50\end{array}$ & $\begin{array}{l}7,80 \\
6,80 \\
6,50 \\
7,00 \\
7,40 \\
6,70\end{array}$ & $\begin{array}{l}6,40 \\
5,50 \\
5,80 \\
5,20 \\
6,50\end{array}$ & $\begin{array}{l}35,00 \\
28,00 \\
32,60 \\
25,00 \\
35,10 \\
33,40\end{array}$ \\
\hline Carlota & $\begin{array}{l}\text { Espada } \\
\text { Extrema } \\
\text { Oliveira Neto } \\
\text { Carlota } \\
\text { Coco } \\
\text { Pahiri }\end{array}$ & $\begin{array}{l}5,50 \\
6,10 \\
4,60 \\
4,50 \\
4,20 \\
5,90\end{array}$ & $\begin{array}{l}5,00 \\
6,40 \\
4,50 \\
5,60 \\
4,60 \\
-\end{array}$ & $\begin{array}{l}5,30 \\
5,20 \\
5,50 \\
6,00 \\
3,70 \\
5,80\end{array}$ & $\begin{array}{l}4,60 \\
4,10 \\
5,30 \\
4,50 \\
5,30 \\
4,60\end{array}$ & $\begin{array}{l}5,60 \\
4,70 \\
5,00 \\
4,80\end{array}$ & $\begin{array}{l}20,40 \\
27,40 \\
24,60 \\
20,60 \\
22,80 \\
21,10\end{array}$ \\
\hline Bourbon & $\begin{array}{l}\text { Espada } \\
\text { Extrema } \\
\text { Oliveira Neto } \\
\text { Carlota } \\
\text { Coco } \\
\text { Pahiri }\end{array}$ & $\begin{array}{l}5,70 \\
6,40 \\
6,70 \\
6,20 \\
5,50 \\
6,10\end{array}$ & $\begin{array}{l}6,80 \\
6,80 \\
6,00 \\
5,50 \\
6,30 \\
7,70\end{array}$ & $\begin{array}{l}6,90 \\
7,30 \\
6,10 \\
6,50 \\
7,20 \\
7,50\end{array}$ & $\begin{array}{l}6,00 \\
5,00 \\
6,10 \\
5,70 \\
7,20 \\
6,30\end{array}$ & $\begin{array}{l}7,30 \\
7,00 \\
7,10 \\
6,60 \\
5,80 \\
0,50\end{array}$ & $\begin{array}{l}32,70 \\
32,50 \\
32,00 \\
36,20 \\
32,00 \\
34,10\end{array}$ \\
\hline
\end{tabular}


Tabela 18 - Diâmetro (m) das copas de 5 variedades de mangueiras sobre 6 diferentes porta-enxertos em Piracicaba, SP, em 1981.

\begin{tabular}{|c|c|c|c|c|c|c|c|}
\hline \multicolumn{2}{|c|}{ Tratamentos } & \multicolumn{5}{|c|}{ Repetições } & \multirow{2}{*}{ TOTAL } \\
\hline Copa & Porta-enxerto & I & II & III & IV & $\mathrm{V}$ & \\
\hline Extrema & $\begin{array}{l}\text { Espada } \\
\text { Extrema } \\
\text { Oliveira Neto } \\
\text { Carlota } \\
\text { Coco } \\
\text { Pahiri }\end{array}$ & $\begin{array}{r}10,40 \\
10,80 \\
9,20 \\
9,60 \\
9,30 \\
9,30\end{array}$ & $\begin{array}{r}9,50 \\
11,40 \\
8,60 \\
10,70 \\
10,30 \\
11,20\end{array}$ & $\begin{array}{r}9,40 \\
9,40 \\
10,20 \\
7,80 \\
8,30 \\
8,00\end{array}$ & $\begin{array}{c}8,70 \\
9,80 \\
9,00 \\
- \\
- \\
10,30\end{array}$ & $\begin{array}{l}10,70 \\
9,00 \\
9,40 \\
10,20 \\
9,70 \\
-\end{array}$ & $\begin{array}{l}48,70 \\
50,40 \\
46,40 \\
38,30 \\
37,60 \\
38,80\end{array}$ \\
\hline Imperial & $\begin{array}{l}\text { Espada } \\
\text { Extrema } \\
\text { Oliveira Neto } \\
\text { Carlota } \\
\text { Coco } \\
\text { Pahiri }\end{array}$ & $\begin{array}{l}9,40 \\
8,30 \\
7,70 \\
9,00 \\
8,00 \\
8,50\end{array}$ & $\begin{array}{l}7,70 \\
- \\
8,80 \\
9,30 \\
9,60 \\
8,00\end{array}$ & $\begin{array}{r}8,40 \\
10,70 \\
8,80 \\
8,70 \\
9,00 \\
9,40\end{array}$ & $\begin{array}{l}10,00 \\
10,30 \\
9,20 \\
9,40 \\
9,40 \\
9,00\end{array}$ & $\begin{array}{l}9,30 \\
9,30 \\
6,00 \\
9,40 \\
9,70 \\
9,20\end{array}$ & $\begin{array}{l}44,80 \\
38,60 \\
40,50 \\
45,80 \\
45,70 \\
44,10\end{array}$ \\
\hline $\begin{array}{l}\text { Olivei- } \\
\text { ra Neto }\end{array}$ & $\begin{array}{l}\text { Espada } \\
\text { Extrema } \\
\text { Oliveira Neto } \\
\text { Carlota } \\
\text { Coco } \\
\text { Pahiri }\end{array}$ & $\begin{array}{r}10,20 \\
10,00 \\
9,60 \\
9,10 \\
10,30 \\
10,90\end{array}$ & $\begin{array}{r}10,20 \\
8,20 \\
9,60 \\
10,70 \\
9,10 \\
9,30\end{array}$ & $\begin{array}{c}10,70 \\
11,40 \\
10,60 \\
- \\
12,00 \\
8,80\end{array}$ & $\begin{array}{r}11,70 \\
10,40 \\
10,30 \\
8,10 \\
10,80 \\
10,10\end{array}$ & $\begin{array}{c}10,30 \\
- \\
9,30 \\
8,50 \\
8,60 \\
9,30\end{array}$ & $\begin{array}{l}53,10 \\
40,00 \\
49,40 \\
36,40 \\
50,80 \\
48,40\end{array}$ \\
\hline Carlota & $\begin{array}{l}\text { Espada } \\
\text { Extrema } \\
\text { Oliveira Neto } \\
\text { Carlota } \\
\text { Coco } \\
\text { Pahiri }\end{array}$ & $\begin{array}{r}9,30 \\
10,10 \\
7,40 \\
8,60 \\
7,00 \\
9,20\end{array}$ & $\begin{array}{l}9,00 \\
9,40 \\
7,10 \\
7,90 \\
7,80 \\
-\end{array}$ & $\begin{array}{r}9,20 \\
9,90 \\
9,00 \\
10,00 \\
7,00 \\
8,30\end{array}$ & $\begin{array}{l}8,50 \\
6,80 \\
9,60 \\
7,50 \\
8,10 \\
7,50\end{array}$ & $\begin{array}{l}- \\
8,30 \\
8,10 \\
- \\
9,00 \\
9,00\end{array}$ & $\begin{array}{l}36,00 \\
44,50 \\
40,60 \\
34,60 \\
38,90 \\
34,00\end{array}$ \\
\hline Bourbon & $\begin{array}{l}\text { Espada } \\
\text { Extrema } \\
\text { Oliveira Neto } \\
\text { Carlota } \\
\text { Coco } \\
\text { Pahiri }\end{array}$ & $\begin{array}{l}8,50 \\
8,80 \\
9,00 \\
8,60 \\
7,60 \\
8,30\end{array}$ & $\begin{array}{l}9,60 \\
8,60 \\
8,00 \\
8,00 \\
8,40 \\
9,30\end{array}$ & $\begin{array}{r}10,00 \\
8,90 \\
9,20 \\
9,20 \\
9,00 \\
10,30\end{array}$ & $\begin{array}{r}9,20 \\
8,40 \\
9,20 \\
9,00 \\
9,80 \\
10,00\end{array}$ & $\begin{array}{r}10,00 \\
9,60 \\
10,40 \\
9,20 \\
7,10 \\
10,20\end{array}$ & $\begin{array}{l}47,30 \\
44,30 \\
45,80 \\
44,00 \\
41,90 \\
48,10\end{array}$ \\
\hline
\end{tabular}


Tabela 19 - Nümero de panículas de 5 variedades de mangueira, sobre 6 dife rentes porta-enxertos (total de 5 repetições) em Piracicaba SP, em 1981.

\begin{tabular}{|c|c|c|c|c|c|c|c|}
\hline \multicolumn{2}{|c|}{ Tratamentos } & \multicolumn{5}{|c|}{ Meses } & \multirow{2}{*}{ TOTAI } \\
\hline Copa & Porta-enxerto & Maio & Junho & Julho & Agosto & Setembro & \\
\hline Extrema & $\begin{array}{l}\text { Espada } \\
\text { Extrema } \\
\text { Oliveira Neto } \\
\text { Carlota } \\
\text { Coco } \\
\text { Pahiri }\end{array}$ & $\begin{array}{r}0 \\
180 \\
170 \\
430 \\
70 \\
40\end{array}$ & $\begin{array}{l}110 \\
250 \\
150 \\
160 \\
130 \\
60\end{array}$ & $\begin{array}{r}1180 \\
870 \\
980 \\
620 \\
1070 \\
500\end{array}$ & $\begin{array}{r}970 \\
1230 \\
970 \\
750 \\
890 \\
1090\end{array}$ & $\begin{array}{l}0 \\
0 \\
0 \\
0 \\
0 \\
0\end{array}$ & $\begin{array}{l}2260 \\
2530 \\
2270 \\
1960 \\
2160 \\
1690\end{array}$ \\
\hline Imperial & $\begin{array}{l}\text { Espada } \\
\text { Extrema } \\
\text { Oliveira Neto } \\
\text { Carlota } \\
\text { Coco } \\
\text { Pahiri }\end{array}$ & $\begin{array}{l}0 \\
0 \\
0 \\
0 \\
0 \\
0\end{array}$ & $\begin{array}{r}0 \\
30 \\
0 \\
10 \\
0 \\
20\end{array}$ & $\begin{array}{l}300 \\
150 \\
260 \\
360 \\
300 \\
350\end{array}$ & $\begin{array}{l}1660 \\
1300 \\
1410 \\
1120 \\
1730 \\
1670\end{array}$ & $\begin{array}{r}130 \\
100 \\
80 \\
110 \\
90 \\
50\end{array}$ & $\begin{array}{l}2090 \\
1580 \\
1750 \\
1600 \\
2120 \\
2090\end{array}$ \\
\hline $\begin{array}{l}\text { Olivei- } \\
\text { ra Neto }\end{array}$ & $\begin{array}{l}\text { Espada } \\
\text { Extrema } \\
\text { Oliveira Neto } \\
\text { Carlota } \\
\text { Coco } \\
\text { Pahiri }\end{array}$ & $\begin{array}{r}20 \\
30 \\
0 \\
0 \\
0 \\
260\end{array}$ & $\begin{array}{r}0 \\
20 \\
0 \\
0 \\
30 \\
50\end{array}$ & $\begin{array}{r}920 \\
630 \\
850 \\
570 \\
840 \\
1010\end{array}$ & $\begin{array}{l}1620 \\
1420 \\
1380 \\
1110 \\
1460 \\
1560\end{array}$ & $\begin{array}{l}0 \\
0 \\
0 \\
0 \\
0 \\
0\end{array}$ & $\begin{array}{l}2560 \\
2100 \\
2230 \\
1680 \\
2330 \\
2880\end{array}$ \\
\hline Carlota & $\begin{array}{l}\text { Espada } \\
\text { Extrema } \\
\text { Oliveira Neto } \\
\text { Carlota } \\
\text { Coco } \\
\text { Pahiri }\end{array}$ & $\begin{array}{l}0 \\
0 \\
0 \\
0 \\
0 \\
0\end{array}$ & $\begin{array}{r}10 \\
0 \\
20 \\
0 \\
0 \\
0\end{array}$ & $\begin{array}{l}320 \\
290 \\
550 \\
250 \\
280 \\
280\end{array}$ & $\begin{array}{l}1870 \\
1830 \\
2390 \\
1940 \\
1860 \\
1610\end{array}$ & $\begin{array}{l}0 \\
0 \\
0 \\
0 \\
0 \\
0\end{array}$ & $\begin{array}{l}2200 \\
2120 \\
2960 \\
2190 \\
2140 \\
1890\end{array}$ \\
\hline Bourbon & $\begin{array}{l}\text { Espada } \\
\text { Extrema } \\
\text { Oliveira Neto } \\
\text { Carlota } \\
\text { Coco } \\
\text { Pahiri }\end{array}$ & $\begin{array}{r}0 \\
30 \\
0 \\
0 \\
90 \\
150\end{array}$ & $\begin{array}{l}100 \\
120 \\
150 \\
260 \\
160 \\
140\end{array}$ & $\begin{array}{l}1420 \\
1340 \\
1280 \\
1530 \\
1410 \\
1680\end{array}$ & $\begin{array}{r}940 \\
980 \\
1280 \\
640 \\
1000 \\
970\end{array}$ & $\begin{array}{l}0 \\
0 \\
0 \\
0 \\
0 \\
0\end{array}$ & $\begin{array}{l}2460 \\
2470 \\
2710 \\
2430 \\
2660 \\
2940\end{array}$ \\
\hline
\end{tabular}


Tabela 20 - Número de panículas de 5 variedades de mangueiras, sobre 6 diferentes porta-enxertos em Piracicaba, SP (total de 5 repetições), em 1982.

\begin{tabular}{|c|c|c|c|c|c|c|c|}
\hline \multicolumn{2}{|c|}{ Tratamentos } & \multicolumn{5}{|c|}{ Meses } & \multirow[b]{2}{*}{ TOTAI } \\
\hline Copa & Porta-enxerto & Maio & Junho & Julho & Agosto & Setembro & \\
\hline Extrema & $\begin{array}{l}\text { Espada } \\
\text { Extrema } \\
\text { Oliveira Neto } \\
\text { Carlota } \\
\text { Coco } \\
\text { Pahiri }\end{array}$ & $\begin{array}{r}20 \\
0 \\
6 \\
12 \\
30 \\
5\end{array}$ & $\begin{array}{l}353 \\
460 \\
542 \\
920 \\
278 \\
553\end{array}$ & $\begin{array}{l}641 \\
646 \\
893 \\
514 \\
331 \\
585\end{array}$ & $\begin{array}{r}53 \\
40 \\
61 \\
293 \\
55 \\
40\end{array}$ & $\begin{array}{l}0 \\
0 \\
0 \\
0 \\
0 \\
0\end{array}$ & $\begin{array}{r}1067 \\
1146 \\
1502 \\
1739 \\
694 \\
1183\end{array}$ \\
\hline Imperial & $\begin{array}{l}\text { Espada } \\
\text { Extrema } \\
\text { Oliveira Neto } \\
\text { Carlota } \\
\text { Coco } \\
\text { Pahiri }\end{array}$ & $\begin{array}{r}22 \\
8 \\
4 \\
53 \\
0 \\
2\end{array}$ & $\begin{array}{r}302 \\
844 \\
626 \\
1255 \\
655 \\
618\end{array}$ & $\begin{array}{r}768 \\
318 \\
704 \\
1099 \\
730 \\
625\end{array}$ & $\begin{array}{r}79 \\
770 \\
324 \\
802 \\
179 \\
299\end{array}$ & $\begin{array}{r}0 \\
22 \\
0 \\
15 \\
0 \\
7\end{array}$ & $\begin{array}{l}1171 \\
1962 \\
1658 \\
3224 \\
1564 \\
1551\end{array}$ \\
\hline $\begin{array}{l}\text { Olivei- } \\
\text { ra Neto }\end{array}$ & $\begin{array}{l}\text { Espada } \\
\text { Extrema } \\
\text { Oliveira Neto } \\
\text { Carlota } \\
\text { Coco } \\
\text { Pahiri }\end{array}$ & $\begin{array}{r}0 \\
20 \\
6 \\
0 \\
0 \\
0\end{array}$ & $\begin{array}{l}238 \\
522 \\
279 \\
416 \\
557 \\
658\end{array}$ & $\begin{array}{l}650 \\
399 \\
758 \\
674 \\
764 \\
609\end{array}$ & $\begin{array}{l}85 \\
78 \\
77 \\
72 \\
44 \\
78\end{array}$ & $\begin{array}{l}0 \\
0 \\
0 \\
0 \\
0 \\
0\end{array}$ & $\begin{array}{r}973 \\
1019 \\
1120 \\
1162 \\
1365 \\
1345\end{array}$ \\
\hline Carlota & $\begin{array}{l}\text { Espada } \\
\text { Extrema } \\
\text { Oliveira Neto } \\
\text { Carlota } \\
\text { Coco } \\
\text { Pahiri }\end{array}$ & $\begin{array}{r}0 \\
30 \\
1 \\
2 \\
0 \\
0\end{array}$ & $\begin{array}{l}132 \\
906 \\
369 \\
432 \\
306 \\
188\end{array}$ & $\begin{array}{l}137 \\
918 \\
690 \\
646 \\
393 \\
498\end{array}$ & $\begin{array}{r}10 \\
77 \\
350 \\
14 \\
19 \\
35\end{array}$ & $\begin{array}{l}0 \\
0 \\
0 \\
0 \\
0 \\
0\end{array}$ & $\begin{array}{r}279 \\
1931 \\
1410 \\
1094 \\
718 \\
721\end{array}$ \\
\hline Bourbon & $\begin{array}{l}\text { Espada } \\
\text { Extrema } \\
\text { Oliveira Neto } \\
\text { Carlota } \\
\text { Coco } \\
\text { Pahiri }\end{array}$ & $\begin{array}{r}20 \\
6 \\
0 \\
10 \\
20 \\
10\end{array}$ & $\begin{array}{l}463 \\
437 \\
349 \\
457 \\
482 \\
867\end{array}$ & $\begin{array}{l}659 \\
588 \\
340 \\
699 \\
609 \\
966\end{array}$ & $\begin{array}{l}100 \\
105 \\
169 \\
100 \\
116 \\
275\end{array}$ & $\begin{array}{l}0 \\
0 \\
0 \\
0 \\
0 \\
0\end{array}$ & $\begin{array}{r}1242 \\
1136 \\
858 \\
1266 \\
1227 \\
2118\end{array}$ \\
\hline
\end{tabular}


Tabela 21 - Número de paríiculas de 5 variedades de mangueira, sobre 6 dife rentes porta-enxertos (total de 5 repetições), em Piracicaba SP, em 1983.

\begin{tabular}{|c|c|c|c|c|c|c|c|}
\hline \multicolumn{2}{|c|}{ Tratamentos } & \multicolumn{2}{|l|}{$\cdot$} & \multicolumn{3}{|l|}{ Meses } & \multirow{2}{*}{ TOTAI } \\
\hline Copa & Porta-enxerto & Maio & Junho & Julho & Agosto & Setembro & \\
\hline Extrema & $\begin{array}{l}\text { Espada } \\
\text { Extrema } \\
\text { Oliveira Neto } \\
\text { Carlota } \\
\text { Coco } \\
\text { Pahiri }\end{array}$ & $\begin{array}{l}8 \\
8 \\
0 \\
0 \\
0 \\
0\end{array}$ & $\begin{array}{l}365 \\
460 \\
542 \\
920 \\
278 \\
553\end{array}$ & $\begin{array}{l}3677 \\
3860 \\
4536 \\
3894 \\
3034 \\
3585\end{array}$ & $\begin{array}{r}53 \\
40 \\
61 \\
293 \\
55 \\
40\end{array}$ & $\begin{array}{r}40 \\
96 \\
0 \\
0 \\
9 \\
10\end{array}$ & $\begin{array}{l}4143 \\
4464 \\
5139 \\
5107 \\
3376 \\
4188\end{array}$ \\
\hline Imperial & $\begin{array}{l}\text { Espada } \\
\text { Extrema } \\
\text { Oliveira Neto } \\
\text { Carlota } \\
\text { Coco } \\
\text { Pahiri }\end{array}$ & $\begin{array}{r}11 \\
0 \\
0 \\
6 \\
0 \\
4\end{array}$ & $\begin{array}{l}356 \\
494 \\
456 \\
962 \\
427 \\
617\end{array}$ & $\begin{array}{l}4005 \\
3477 \\
5924 \\
3077 \\
3041 \\
3730\end{array}$ & $\begin{array}{r}97 \\
770 \\
351 \\
793 \\
179 \\
299\end{array}$ & $\begin{array}{r}4 \\
5 \\
4 \\
10 \\
5 \\
5\end{array}$ & $\begin{array}{l}4473 \\
4746 \\
6735 \\
4848 \\
3652 \\
4653\end{array}$ \\
\hline $\begin{array}{l}\text { Olivei- } \\
\text { ra Neto }\end{array}$ & $\begin{array}{l}\text { Espada } \\
\text { Extrema } \\
\text { Oliveira Neto } \\
\text { Carlota } \\
\text { Coco } \\
\text { Pahiri }\end{array}$ & $\begin{array}{l}0 \\
3 \\
0 \\
0 \\
0 \\
0\end{array}$ & $\begin{array}{r}24 \\
722 \\
244 \\
381 \\
466 \\
444\end{array}$ & $\begin{array}{l}4523 \\
4833 \\
5330 \\
4673 \\
4606 \\
5546\end{array}$ & $\begin{array}{l}85 \\
78 \\
77 \\
72 \\
40 \\
78\end{array}$ & $\begin{array}{r}1 \\
10 \\
2 \\
0 \\
1 \\
1\end{array}$ & $\begin{array}{l}4633 \\
5646 \\
5653 \\
5126 \\
5113 \\
6069\end{array}$ \\
\hline Carlota & $\begin{array}{l}\text { Espada } \\
\text { Extrema } \\
\text { Oliveira Neto } \\
\text { Carlota } \\
\text { Coco } \\
\text { Pahiri }\end{array}$ & $\begin{array}{l}8 \\
0 \\
0 \\
0 \\
4 \\
0\end{array}$ & $\begin{array}{r}8 \\
692 \\
31 \\
124 \\
93 \\
120\end{array}$ & $\begin{array}{l}3246 \\
4254 \\
3806 \\
3896 \\
3628 \\
3828\end{array}$ & $\begin{array}{r}10 \\
77 \\
350 \\
14 \\
19 \\
35\end{array}$ & $\begin{array}{l}7 \\
0 \\
3 \\
8 \\
2 \\
0\end{array}$ & $\begin{array}{l}3279 \\
5023 \\
4190 \\
4042 \\
3746 \\
3983\end{array}$ \\
\hline Bourbon & $\begin{array}{l}\text { Espada } \\
\text { Extrema } \\
\text { Oliveira Neto } \\
\text { Carlota } \\
\text { Coco } \\
\text { Pahiri }\end{array}$ & $\begin{array}{l}0 \\
0 \\
0 \\
0 \\
0 \\
0\end{array}$ & $\begin{array}{l}412 \\
400 \\
342 \\
500 \\
510 \\
768\end{array}$ & $\begin{array}{l}3668 \\
5007 \\
3880 \\
5768 \\
4589 \\
5056\end{array}$ & $\begin{array}{l}100 \\
105 \\
169 \\
100 \\
116 \\
275\end{array}$ & $\begin{array}{l}1 \\
1 \\
0 \\
0 \\
1 \\
0\end{array}$ & $\begin{array}{l}4181 \\
5513 \\
4391 \\
6368 \\
5216 \\
6099\end{array}$ \\
\hline
\end{tabular}


Tabela 22 - Núnero de frutos de 5 variedades de mangueira, sobre 6 diferentes porta-enxertos, em Piracicaba, SP, em 1981.

\begin{tabular}{|c|c|c|c|c|c|c|c|}
\hline \multicolumn{2}{|c|}{ Tratamentos } & \multicolumn{5}{|c|}{ Repetições } & \multirow{2}{*}{ TOTAL } \\
\hline Copa & Porta-enxerto & $\mathrm{I}$ & II & III & IV & $\mathrm{V}$ & \\
\hline Extrema & $\begin{array}{l}\text { Espada } \\
\text { Extrema } \\
\text { Oliveira Neto } \\
\text { Carlota } \\
\text { Coco } \\
\text { Pahiri }\end{array}$ & $\begin{array}{l}225 \\
278 \\
301 \\
359 \\
348 \\
324\end{array}$ & $\begin{array}{l}370 \\
305 \\
385 \\
220 \\
348 \\
313\end{array}$ & $\begin{array}{l}327 \\
348 \\
230 \\
185 \\
343 \\
268\end{array}$ & $\begin{array}{l}310 \\
329 \\
468 \\
- \\
\overline{4}\end{array}$ & $\begin{array}{l}316 \\
220 \\
390 \\
267 \\
342 \\
-\end{array}$ & $\begin{array}{l}1548 \\
1480 \\
1774 \\
1004 \\
1381 \\
1360\end{array}$ \\
\hline Imperial & $\begin{array}{l}\text { Espada } \\
\text { Extrema } \\
\text { Oliveira Neto } \\
\text { Carlota } \\
\text { Coco } \\
\text { Pahiri }\end{array}$ & $\begin{array}{l}537 \\
465 \\
362 \\
346 \\
511 \\
598\end{array}$ & $\begin{array}{c}404 \\
- \\
390 \\
668 \\
522 \\
410\end{array}$ & $\begin{array}{l}366 \\
238 \\
216 \\
260 \\
335 \\
346\end{array}$ & $\begin{array}{l}242 \\
363 \\
406 \\
290 \\
430 \\
337\end{array}$ & $\begin{array}{l}291 \\
135 \\
122 \\
200 \\
304 \\
183\end{array}$ & $\begin{array}{l}1840 \\
1201 \\
1496 \\
1764 \\
2102 \\
1874\end{array}$ \\
\hline $\begin{array}{l}\text { Olivei- } \\
\text { ra Neto }\end{array}$ & $\begin{array}{l}\text { Espada } \\
\text { Extrema } \\
\text { Oliveira Neto } \\
\text { Carlota } \\
\text { Coco } \\
\text { Pahiri }\end{array}$ & $\begin{array}{l}411 \\
577 \\
489 \\
406 \\
515 \\
470\end{array}$ & $\begin{array}{l}623 \\
405 \\
523 \\
446 \\
456 \\
487\end{array}$ & $\begin{array}{c}514 \\
700 \\
506 \\
- \\
565 \\
392\end{array}$ & $\begin{array}{l}700 \\
535 \\
678 \\
607 \\
616 \\
520\end{array}$ & $\begin{array}{l}530 \\
435 \\
381 \\
297 \\
510\end{array}$ & $\begin{array}{l}2778 \\
2217 \\
2631 \\
1840 \\
2449 \\
2379\end{array}$ \\
\hline Carlota & $\begin{array}{l}\text { Espada } \\
\text { Extrema } \\
\text { Oliveira Neto } \\
\text { Carlota } \\
\text { Coco } \\
\text { Pahiri }\end{array}$ & $\begin{array}{l}771 \\
690 \\
727 \\
924 \\
614 \\
834\end{array}$ & $\begin{array}{l}814 \\
647 \\
500 \\
558 \\
652 \\
-\end{array}$ & $\begin{array}{l}625 \\
816 \\
863 \\
789 \\
400 \\
450\end{array}$ & $\begin{array}{l}413 \\
427 \\
794 \\
600 \\
381 \\
629\end{array}$ & $\begin{array}{l}3 \overline{3} 4 \\
505 \\
4 \overline{3} 0 \\
550\end{array}$ & $\begin{array}{l}2623 \\
2914 \\
3389 \\
2871 \\
2477 \\
2463\end{array}$ \\
\hline Bourbon & $\begin{array}{l}\text { Espada } \\
\text { Extrema } \\
\text { Oliveira Neto } \\
\text { Carlota } \\
\text { Coco } \\
\text { Pahiri }\end{array}$ & $\begin{array}{l}572 \\
400 \\
454 \\
483 \\
419 \\
410\end{array}$ & $\begin{array}{l}604 \\
600 \\
556 \\
320 \\
334 \\
612\end{array}$ & $\begin{array}{l}571 \\
381 \\
518 \\
485 \\
600 \\
690\end{array}$ & $\begin{array}{l}463 \\
344 \\
500 \\
510 \\
471 \\
440\end{array}$ & $\begin{array}{l}364 \\
300 \\
420 \\
258 \\
280 \\
235\end{array}$ & $\begin{array}{l}2574 \\
2025 \\
2448 \\
2056 \\
2104 \\
2387\end{array}$ \\
\hline
\end{tabular}


Tabela 23 - Niunero de frutos de 5 variedades de mangueira, sobre 6 diferentes porta-enxertos em Piracicaba, SP, en 1982.

\begin{tabular}{|c|c|c|c|c|c|c|c|}
\hline \multicolumn{2}{|c|}{ Tratamentos } & \multicolumn{5}{|c|}{ Repetiçōes } & \multirow{2}{*}{ TOTAL } \\
\hline Copa & Porta-enxerto & I & II & III & IV & $\mathrm{V}$ & \\
\hline Extrema & $\begin{array}{l}\text { Espada } \\
\text { Extrema } \\
\text { Oliveira Neto } \\
\text { Carlota } \\
\text { Coco } \\
\text { Pahiri }\end{array}$ & $\begin{array}{r}128 \\
22 \\
64 \\
193 \\
149 \\
102\end{array}$ & $\begin{array}{r}3 \\
70 \\
170 \\
227 \\
11 \\
28\end{array}$ & $\begin{array}{r}23 \\
29 \\
35 \\
85 \\
1 \\
78\end{array}$ & $\begin{array}{r}0 \\
0 \\
50 \\
2 \\
\overline{0}\end{array}$ & $\begin{array}{r}2 \\
39 \\
2 \\
98 \\
31 \\
-\end{array}$ & $\begin{array}{l}156 \\
160 \\
321 \\
605 \\
192 \\
208\end{array}$ \\
\hline Inperial & $\begin{array}{l}\text { Espada } \\
\text { Extrema } \\
\text { Oliveira Neto } \\
\text { Carlota } \\
\text { Coco } \\
\text { Pahiri }\end{array}$ & $\begin{array}{r}0 \\
0 \\
1 \\
170 \\
0 \\
2\end{array}$ & $\begin{array}{l}8 \\
-1 \\
0 \\
0 \\
0\end{array}$ & $\begin{array}{r}3 \\
562 \\
155 \\
338 \\
170 \\
116\end{array}$ & $\begin{array}{r}58 \\
0 \\
58 \\
47 \\
7 \\
45\end{array}$ & $\begin{array}{r}19 \\
122 \\
136 \\
195 \\
39 \\
104\end{array}$ & $\begin{array}{l}88 \\
684 \\
351 \\
750 \\
216 \\
267\end{array}$ \\
\hline $\begin{array}{l}\text { Olivei- } \\
\text { ra Neto }\end{array}$ & $\begin{array}{l}\text { Espada } \\
\text { Extrema } \\
\text { Oliveira Neto } \\
\text { Carlota } \\
\text { Coco } \\
\text { Pahiri }\end{array}$ & $\begin{array}{r}75 \\
0 \\
92 \\
81 \\
0 \\
122\end{array}$ & $\begin{array}{r}0 \\
0 \\
14 \\
46 \\
0 \\
0\end{array}$ & $\begin{array}{r}134 \\
129 \\
23 \\
11 \\
8 \\
0\end{array}$ & $\begin{array}{l}0 \\
1 \\
8 \\
0 \\
3 \\
0\end{array}$ & $\begin{array}{r}0 \\
427 \\
405 \\
76 \\
94 \\
284\end{array}$ & $\begin{array}{l}209 \\
557 \\
542 \\
214 \\
105 \\
370\end{array}$ \\
\hline Carlota & $\begin{array}{l}\text { Espada } \\
\text { Extrema } \\
\text { Oliveira Neto } \\
\text { Carlota } \\
\text { Coco } \\
\text { Pahiri }\end{array}$ & $\begin{array}{l}0 \\
71 \\
11 \\
52 \\
21 \\
54\end{array}$ & $\begin{array}{r}0 \\
163 \\
40 \\
129 \\
11 \\
-\end{array}$ & $\begin{array}{r}39 \\
27 \\
41 \\
70 \\
1 \\
109\end{array}$ & $\begin{array}{r}9 \\
31 \\
54 \\
25 \\
107 \\
31\end{array}$ & $\begin{array}{r}347 \\
1 \\
-\overline{51} \\
104\end{array}$ & $\begin{array}{r}48 \\
639 \\
147 \\
276 \\
191 \\
298\end{array}$ \\
\hline Bourbon & $\begin{array}{l}\text { Espada } \\
\text { Extrema } \\
\text { Oliveira Neto } \\
\text { Carlota } \\
\text { Coco } \\
\text { Pahiri }\end{array}$ & $\begin{array}{r}29 \\
6 \\
61 \\
6 \\
0 \\
145\end{array}$ & $\begin{array}{r}0 \\
62 \\
101 \\
36 \\
14 \\
224\end{array}$ & $\begin{array}{r}1 \\
64 \\
1 \\
0 \\
9 \\
61\end{array}$ & $\begin{array}{r}0 \\
48 \\
38 \\
63 \\
4 \\
1\end{array}$ & $\begin{array}{r}9 \\
36 \\
44 \\
98 \\
29 \\
72\end{array}$ & $\begin{array}{r}39 \\
216 \\
245 \\
203 \\
56 \\
503\end{array}$ \\
\hline
\end{tabular}


Tabela 24 - Número de frutos de 5 variedades de mangueira, sobre 6 diferentes porta-enxertos em Piracicaba, SP, em 1983.

\begin{tabular}{|c|c|c|c|c|c|c|c|}
\hline \multicolumn{2}{|c|}{ Tratamentos } & \multicolumn{5}{|c|}{ Repetições } & \multirow{2}{*}{ TOTAL } \\
\hline Copa & Porta-enxerto & $I$ & II & III & IV & $\mathrm{v}$ & \\
\hline Extrema & $\begin{array}{l}\text { Espada } \\
\text { Extrema } \\
\text { Oliveira Neto } \\
\text { Carlota } \\
\text { Coco } \\
\text { Pahiri }\end{array}$ & $\begin{array}{l}388 \\
286 \\
283 \\
281 \\
202 \\
321\end{array}$ & $\begin{array}{r}391 \\
239 \\
87 \\
197 \\
96 \\
197\end{array}$ & $\begin{array}{r}173 \\
209 \\
130 \\
192 \\
450 \\
87\end{array}$ & $\begin{array}{r}155 \\
45 \\
126 \\
3 \\
- \\
108\end{array}$ & $\begin{array}{l}135 \\
237 \\
170 \\
237 \\
131 \\
-\end{array}$ & $\begin{array}{r}1244 \\
1016 \\
796 \\
910 \\
879 \\
713\end{array}$ \\
\hline Imperial & $\begin{array}{l}\text { Espada } \\
\text { Extrema } \\
\text { Oliveira Neto } \\
\text { Carlota } \\
\text { Coco } \\
\text { Pahiri }\end{array}$ & $\begin{array}{r}8 \\
25 \\
34 \\
73 \\
37 \\
34\end{array}$ & $\begin{array}{c}8 \\
-7 \\
- \\
9 \\
7\end{array}$ & $\begin{array}{l}23 \\
45 \\
63 \\
19 \\
78 \\
10\end{array}$ & $\begin{array}{r}29 \\
16 \\
6 \\
14 \\
23 \\
8\end{array}$ & $\begin{array}{r}14 \\
62 \\
46 \\
15 \\
9 \\
47\end{array}$ & $\begin{array}{r}82 \\
148 \\
156 \\
121 \\
156 \\
106\end{array}$ \\
\hline $\begin{array}{l}\text { Olivei- } \\
\text { ra Neto }\end{array}$ & $\begin{array}{l}\text { Espada } \\
\text { Extrema } \\
\text { Oliveira Neto } \\
\text { Carlota } \\
\text { Coco } \\
\text { Pahiri }\end{array}$ & $\begin{array}{l}115 \\
236 \\
305 \\
236 \\
236 \\
197\end{array}$ & $\begin{array}{l}183 \\
222 \\
271 \\
116 \\
290 \\
199\end{array}$ & $\begin{array}{r}63 \\
144 \\
100 \\
1 \\
115 \\
63\end{array}$ & $\begin{array}{r}68 \\
86 \\
133 \\
91 \\
80 \\
80\end{array}$ & $\begin{array}{r}192 \\
42 \\
166 \\
176 \\
132 \\
319\end{array}$ & $\begin{array}{l}621 \\
730 \\
975 \\
620 \\
853 \\
858\end{array}$ \\
\hline Carlota & $\begin{array}{l}\text { Espada } \\
\text { Extrema } \\
\text { Oliveira Neto } \\
\text { Carlota } \\
\text { Coco } \\
\text { Pahiri }\end{array}$ & $\begin{array}{r}167 \\
- \\
203 \\
337 \\
94 \\
294\end{array}$ & $\begin{array}{r}50 \\
131 \\
101 \\
101 \\
159 \\
-\end{array}$ & $\begin{array}{l}32 \\
55 \\
66 \\
53 \\
38 \\
37\end{array}$ & $\begin{array}{r}407 \\
115 \\
125 \\
203 \\
332 \\
60\end{array}$ & $\begin{array}{r}\overline{8} \\
40 \\
\overline{4} \\
159\end{array}$ & $\begin{array}{l}656 \\
383 \\
535 \\
694 \\
665 \\
550\end{array}$ \\
\hline Bourbon & $\begin{array}{l}\text { Espada } \\
\text { Extrema } \\
\text { Oliveira Neto } \\
\text { Carlota } \\
\text { Coco } \\
\text { Pahiri }\end{array}$ & $\begin{array}{r}4 \\
12 \\
4 \\
3 \\
5 \\
5\end{array}$ & $\begin{array}{r}7 \\
-5 \\
13 \\
24 \\
3\end{array}$ & $\begin{array}{l}2 \\
1 \\
3 \\
3 \\
3 \\
2\end{array}$ & $\begin{array}{l}3 \\
1 \\
8 \\
2 \\
5 \\
8\end{array}$ & $\begin{array}{l}3 \\
0 \\
0 \\
3 \\
1 \\
2\end{array}$ & $\begin{array}{l}19 \\
14 \\
20 \\
24 \\
38 \\
20\end{array}$ \\
\hline
\end{tabular}

